Military Technical College Kobry El-Kobba

Cairo, Egypt

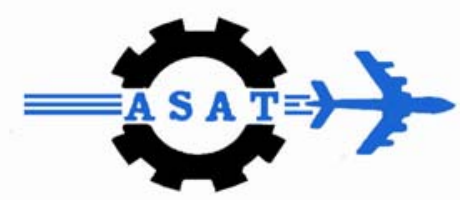

12-th International Conference on

Aerospace Sciences \& Aviation Technology

\title{
PRELIMINARY DESIGN FOR SATELLITE THERMAL CONTROL SYSTEM
}

\author{
Prof. Dr. Youssef Ahmed Mohamed Elgendy \\ Head of Thermal Control Division, Egyptian Satellite Program \\ National Authority for Remote Sensing \& Space Sciences (NARSS) \\ elgendy51@hotmail.com \\ youssefelgendy@yahoo.com
}

\begin{abstract}
The purpose of this research is to determine the temperatures distribution of the satellite subsystems such as: MBEI, MIREI, GPS, Mt, MM, RW, SS, PCDHS, SF, SPU, Tel, and IB in order to determine the worst-case hot temperature (WCH) \& worst-case cold temperature (WCC) expressions of the satellite and to study the continuously variable environmental and operating parameters of the LEO satellite to develop a preliminary design for a satellite thermal control subsystem. Also, the temperature of the PVC and external satellite surface are determined. This purpose will lead to maintain and continuously safely operate for all elements of the satellite subsystems within the allowed temperature limits, for all mission phases over the mission lifetime, subject to given ranges of environmental conditions and operating modes.
\end{abstract}

In this paper, the heat transfer models using finite difference codes for the base plate, basis plate, mounting plate, the external body surface, and the photovoltaic cell surface for the satellite are developed. An analytical thermal model is constructed. The heat sources and sinks, both external and internal, such as electronics packages, heaters, cooling devices, and radiators, node/network and thermal resistances between each pair of nodes are identified. The initial conditions and boundary conditions for start-up one orbital revolution, and after 6-revolution are selected.

The thermal analysis for each satellite's component on the: base plate, basis plate, mounting plate, the satellite external body surface, and the photovoltaic surfaces are presented to determine the temperature distribution for steady state and transient conditions at various ranges of initial temperatures and boundary temperatures conditions.

\section{KEYWORD}

Thermal control spacecraft, microsatellite, heat pipe, cooling satellite payload, and cooling electric/electronic/mechanical devices. 


\section{NOMENCLATURE}

$A, A_{p}, A_{r}, A_{s p h}$ heat transfer surface area, projected area of the array, the area of the bottom of the array $\left(1.6 \mathrm{~m}^{2}\right)$, Surface area of the sphere satellite

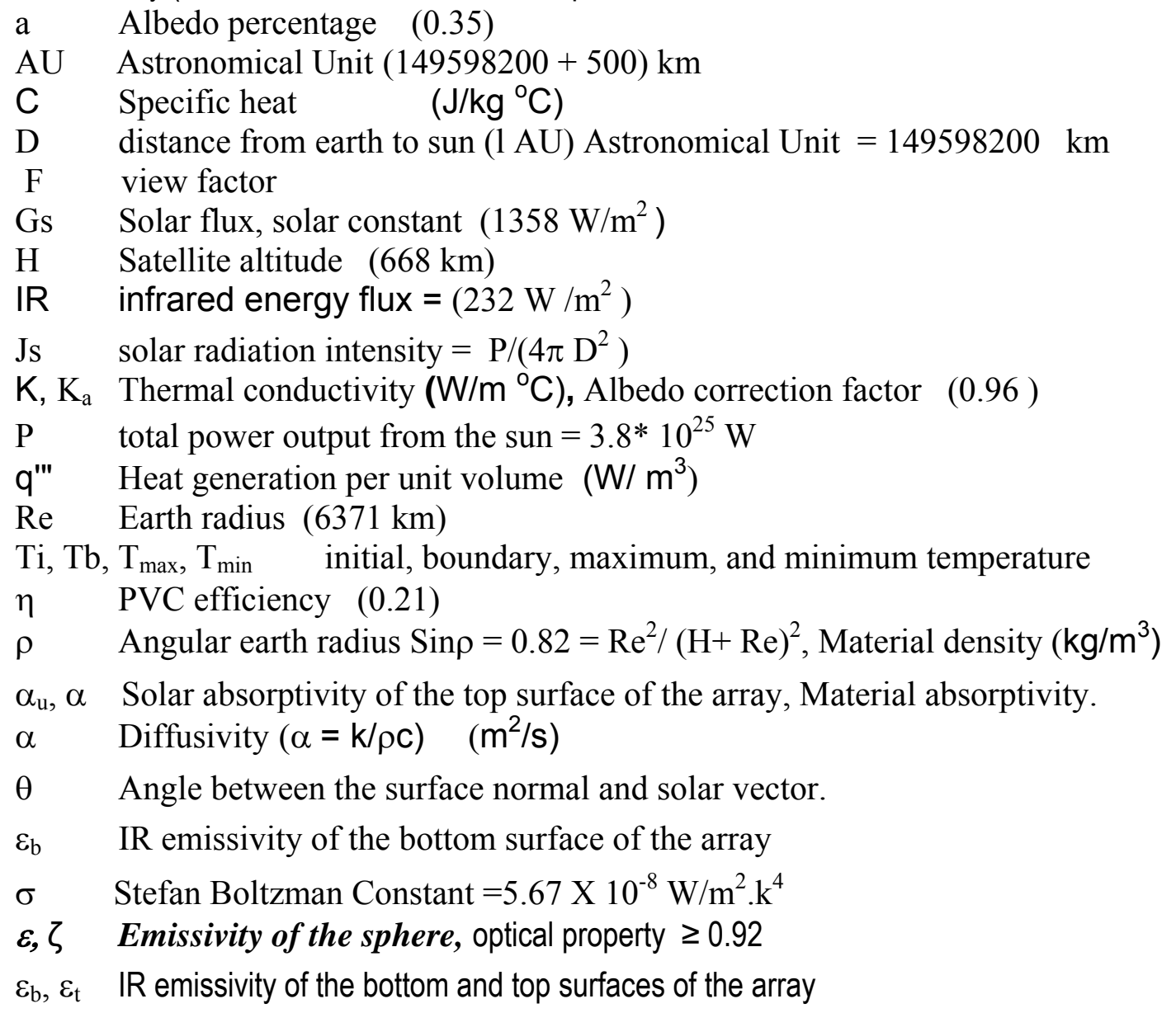

\section{ACRONYMS}

\begin{tabular}{llll} 
ACS & \multicolumn{2}{l}{ Cross section area of the spherical satellite } & \\
IB & Interference Blocks & H & Satellite altitude \\
GPS & Global Positioning System & Mt & Magnetorquers \\
MBEI & Multi-band earth imager & SPU & Signal Processing Unit \\
MIREI & Middle Infra Red (IR) Earth Imager & & SS Star Sensor \\
RW & Reaction Wheels $(x, y, z)$ & MM & Magnetometer \\
SF & Store \& Forward Communication & TD & Temperature distribution \\
Tel & Telemetry & T & Temperature \\
TCS & Thermal control subsystem & WCH & Worst-case hot temperature \\
WCC & Worst-case cold temperature & & \\
PCDHS & Payload Command \& Data Handling Subsystem \\
PVC & Photovoltaic Cell
\end{tabular}




\section{INTRODUCTION}

The purpose of the satellite thermal control subsystem is to control and maintain satellite component temperatures, such as MBEI, MIREI, GPS, Mt, MM, RW, SS, PCDHS, SF, SPU, Tel, and IB, within their specified T limits throughout all mission phases. In larger satellites, this task is accomplished primarily through the use of active thermal control methods such as thermostatically controlled heaters, louvers, and radiator. Micro satellites, however, require more of passive approach due to the severe restrictions on both mass and power budget. An in-depth thermal analysis requires the mechanical design of all subsystems to be relatively complete. Since the determination of the overall mechanical design of Egyptsat-2 is still in progress, this report will include the determination of thermal environment, component $\mathrm{T}$ limits, general guidelines for satellite thermal design, and temperatures analysis to assist in design of thermal control system for Egyptian satellites.

The purpose of this study is the determination of composition and main technical characteristics of the Egyptian satellite thermal control subsystem; conducting of calculations of the satellite thermal conditions that confirm selected characteristics of the thermal subsystem; agreement and updating of requirements of the specifications for development of the thermal subsystem.

In this research, the heat transfer models are developed using finite difference codes. For accurate thermal analysis of a spacecraft, it is necessary to construct an analytical thermal model; this requires identification of heat sources and sinks, both external and internal, such as electronics packages, heaters, cooling devices, and radiators. Nodes are then defined (node/network), usually major items of structure, tanks, and electronic units. Thermal resistances between each pair of nodes that are thermally connected must be determined. This will involve radiation, conduction or both heat transfer modes. Thus, determination of the thermal resistance will involve conductivity of materials and joints as well as emissivity and absorptivity of the surface. Once constructed, the model can be used to solve steady-state problems as well as transient problems by the use of explicit finite-difference codes. Often the model proceeds in an evolutionary manner, with the nodes initially being relatively few and large and the thermal resistance having broad tolerances. At this stage the model may be amenable to hand calculation analysis and the use of simple codes for quick estimates. As the design of the spacecraft matures, the model will become more complex and detailed, dictating computer analysis.

The basis for development of the preliminary design for the thermal control subsystem is the "Satellite Specifications" and "Thermal subsystem Specifications" Taking into account the requirements presented to the satellite and its configuration, satellite mass, dimensions, and power consumption, required thermal conditions of devices and structural elements can be provided by a passive thermal subsystem. This preliminary design describes composition and main characteristics of the thermal subsystem. It includes initial data needed for thermal analysis, describes geometrical and mathematical models of the satellite thermal conditions, contains selection of cases to be analyzed, and results of thermal analysis. The preliminary design defines a scope of tests of the thermal subsystem needed to prove correctness of the selected mathematical model and verify the thermal subsystem characteristics. 
The thermal subsystem includes the following elements: heat shields, multilayer insulation, thermal control coatings, heat insulators, and T sensors as explained below:

- Heat shields which preclude direct influence of external heat flux on the satellite equipment and structural elements placed inside the satellite body between the base and mounting plate,

- Multilayer insulation blankets intended to reduce heat exchange between the satellite equipment and space environment,

- Thermal control coatings with selected values of parameters $\alpha$ and $\varepsilon$. to provide required level of radiant heat exchange between the satellite components and space environment,

- Heat insulators intended to reduce thermal influence of the structure on the satellite equipment, and

- Temperature sensors (resistance thermometers) intended to measure T of the satellite equipment and structural elements.

The thermal control subsystem does not consume power.

\section{THERMAL ENVIRONMENT}

A complete understanding of the thermal environments that satellite will experience is critical for an effective thermal control subsystem design. The thermal environment in Low Earth Orbit (LEO) is defined. Table 1 summarizes the heat loads on Egyptsat-1 in LEO. Also, the design and operating parameters are considered in the preliminary design. Design parameters are determined to design each thermal subsystem's component, such as: sizing, configuration, type of material, properties of material, surface coating properties, coefficient of heat transfer, thermal load, $\mathrm{T}$ range, $\mathrm{T}$ radiant,...etc. Each thermal hardware component is subject to operate variables such as: operating temperature, pressure, amount of heat generated...etc. which are defined.

\section{TEMPERATURE LIMITS}

Establishing the $\mathrm{T}$ specifications for each subsystem components, under which the satellite is to exist during various stages of its life, are necessary for preliminary thermal design. Table (2) shows list of $T$ specifications for some subsystem components [2-6]. These $T$ specifications must be determined as practical ranges early in a program to negotiate the requirements and margins for acceptable thermal control design. The major factors influencing the thermal analysis are dissipated heats, the manner of packaging, mounting procedures, and locations in the satellite. Subsystems that did not have any information regarding component $\mathrm{T}$ limits had $\mathrm{T}$ ranges assigned to them based on information from prior missions.

Table 2 represents the components T limits for electric, electronic, mechanical, and/or optical components of satellites [7-15]. The thermal subsystem during the satellite lifetime should provide: a T of satellite environment within a range from minus $10^{\circ} \mathrm{C}$ to plus $45^{\circ} \mathrm{C}$ for electronic components of the power subsystem (except the battery and solar array panels), telemetry module, store \& forward communication payload, GPS receiver, attitude determination and control subsystem, communication subsystem, on-board computer, signal processing units of multi-band Earth imager and middle IR Earth imager, payload command \& data subsystem placed inside the satellite body 
bounded by the base, mounting plate, and heat shields; for the battery a $\mathrm{T}$ within a range from plus $5^{\circ} \mathrm{C}$ to plus $25^{\circ} \mathrm{C}$ for $90 \%$ of the lifetime and from plus $25^{\circ} \mathrm{C}$ to plus $35^{\circ} \mathrm{C}$ for $10 \%$ of the lifetime.

The thermal subsystem should provide $\mathrm{T}$ within the stated ranges during variations of daily average power dissipated by the satellite equipment from 32.35 to $56.26 \mathrm{~W}$. The thermal subsystem is a passive one. The thermal subsystem should provide the required technical characteristics after separation from the launch vehicle for 5-year lifetime on the Sun-synchronous orbit with the following nominal initial parameters: altitude $\sim 668 \mathrm{~km}$; inclination $\sim 98.085 \mathrm{deg}$, and local time of descending node $\sim$ 10:30.

\section{DESCRIPTION OF STRUCTURE}

The satellite body with dimensions of $636 \times 636 \times 687 \mathrm{~mm}$ includes a stack of frame modules fastened with pins between the base and mounting plate. The frame modules are $380 \times 326 \mathrm{~mm}$ in section. The dimensions of the base and mounting plate are $636 \times 636 \mathrm{~mm}$. The satellite general view from outside is presented in Fig.(1) and from inside as a general view with illustrating the base, basis, and mounting plates in Figs. $(2,3)$. Fig.(2) shows the frame modules and on board equipment. The sides of the frame modules are fixed under an angle of $\left(45^{\circ}\right)$ to the sides of the base and mounting plate. The electrical connectors and cables are placed on the sides of the frame modules. The battery module is next to the base plate. The other frame modules are installed in the following sequence: frame modules of the cells levelling unit, power conditioning unit, GPS receiver, S-band equipment (two modules), basis unit case, frame modules of the X-band equipment, and on-board computer (three modules one of which is adjacent to the mounting plate). The placement of the frame modules and on-board equipment in the satellite body is presented in Fig.(2). Figs.(2, 3) represents the basis, base, and mounting plate.

Installed on the basis unit are the following elements: inside the body -four reaction wheels and four gyros, outside of the body' on brackets -magnetorquers and magnetometer, on the plate of the basis unit star sensor, optical-mechanical units of the MBEI and MIREI. Drawings of installation of equipment on the basis unit are presented. All the surfaces of the basis unit are coated with thermal control coating AK-573. The star sensor, brackets of the optical-mechanical units of the MBEI and MIREI are fixed to the basis unit plate through heat insulators. All the heat insulators are washers made of pressed material DSV-2. The thickness of the washers is not less than $4 \mathrm{~mm}$. The outer diameter of the heat insulators for the optical-mechanical unit of the MBEI is $18 \mathrm{~mm}$, for the optical-mechanical unit of the MIREI $-16 \mathrm{~mm}$, for the bolt M8, bolts M5 and guide pins $08 \mathrm{~h} 7$ used to fix the star sensor $-18 \mathrm{~mm}$. Outside on the base the antennas of the S-band equipment, GPS receiver, and holes for pyrolocks of the launch vehicle adapter are placed. The base has a hole in the plane I for the star sensor blend.

On the inside surface of the base close to the frame modules the MBEI signal processing units and telemetry module are mounted as shown in Fig.(3). On the outside surface of the mounting plate two S-band equipment antennas, GPS receiver antenna, X-band equipment antenna, and store \& forward communication payload antennas are installed. The mounting plate has holes in the planes for the MBEI and MIREI optical-mechanical units. On the inside surface of the mounting plate close to 
the frame modules, the MIREI signal processing units, unit of the payload command \& data handling subsystem, and module of the store \& forward communication payload are installed. The holes in the base and mounting plate are closed with protective covers made of AMg6 sheets with a thickness of $0.5 \mathrm{~mm}$. The side surfaces of the satellite body are covered with the heat shields with dimensions $692 \times 636 \mathrm{~mm}$ made of AM g6 sheets with a thickness of $0.2 \mathrm{~mm}$. Both sides of the heat shields are painted with thermal control enamel AK-243 according to OST 92-9080-90 with the following optical properties: As $\geq 0.95, \zeta \geq 0.92$

The surfaces of the star sensor, MBEI and MIREI optical-mechanical units, all the surfaces of the base and mounting plate (excluding the mounting holes), and protective covers are coated with the thermal control coating AK-243. The external surfaces of the MBEI and MIREI optical-mechanical units (including the brackets) and star sensor (excluding the pupils) are covered with multilayer insulation blankets EVTI2B (10 layers) which have openings for heat sink from the side of the plane. The dimensions of openings are determined after performing thermal analysis.

The frame modules external surfaces and bodies of devices installed on the internal surfaces of the base and mounting plate are coated with AK-573 with the following optical properties: As $\leq 0.24$ and $\zeta \geq 0.85$. The inside surfaces of the frame modules are anodized and oxidized with nichrome. Optical properties of the satellite equipment and structural elements are presented in Table 3.

\section{SATELLITE THERMAL ANALYSIS}

The concept of a 'top down' design flow chart is illustrated in chart 1 for a thermal control system (TCS). In order to determine bulk satellite temperatures, steady state and transient $T$ analyses are performed. Results of these analyse are reported. In order to perform a basic thermal analysis, the following assumptions are required:

- The main body of the satellite is considered as an idealized thermal system with one dissipating interior region exchanging heat with a boundary (ambient).

- In steady state condition, the heat dissipated in the interior equals heat transferred to the radiator.

- At the boundary, the heat from internal dissipation plus heat absorbed from outside equal's heat rejected to space.

- In space, convection heat transfer mode can be neglected because of vacuum; the $\mathrm{T}$ in space is almost $2.7^{\circ} \mathrm{K}$, very close to absolute zero, therefore, no heat transfer between hot and cold air as on the earth and no difference in density of gases.

- Radiation heat transfer mode is the only heat transfer mode involved in space heat source dissipaters, solar, albedo, and earth flux; no other energy sources are present.

- The satellite's body may be assumed as an isothermal body, which will benefit its reliability; this approach could lead to high power dissipation density. Consequently, a small-scale heat pipes and pumped fluid loops can be utilized [5-8].

- The instrument must be conductively isolated from the satellite; some amount of radiator area will be required to reject the instrument waste heat to the space. 
Heat transfer mathematical models are developed to determine the WHC and WCC expressions of the satellite structural units and on-board equipment. In this research, three heat transfer models are studied for the following satellite subcomponents:

1- The base, basis, mounting plates, and frame module;

2- Satellite PV cell; and

3- Satellite external body.

\section{THERMAL ANALYSIS FOR THE BASE, BASIS, and MOUNTING PLATE}

The objectives of this part are to determine the $\mathrm{WCH}, \mathrm{WCC}$ expressions for the base, basis and mounting plates, and to obtain the TD. The general heat transfer by conduction mode with heat generation for each plate is applied with technical considerations.

The daily average power consumption, which represents the heat generation by the main subsystem components, that considered as the heat sources, or heat dissipation throughout the subcomponents, optical properties are represented in Tables $(3,4)$ for the base plate, basis plate, mounting plate, and frame module for the four heat transfer models. Also, the overall dimensions for the subsystems are reported. The following assumptions are chosen for approximation and some lake of information and data which are not available at this moment.

- Uniform thermal conductivity (isotropic material) for the base, the basis and the mounting plates

- Two dimension heat transfer model

- The increments of the space coordinates, in two dimension, are chosen equal such that $X=Y=90 \mathrm{~mm}$,

- Working on the worst case, all power dissipation changes into heat dissipation,

- The boundary conditions around the plate's temperatures are constant for startup,

- The initial condition at start-up for all nodes is equals, considered to be constant

- In order to simplify the heat transfer model, the radiation effect is neglected due to the limitation of the upper-limit $\mathrm{T}$ of the heat source component $\left(70{ }^{\circ} \mathrm{C}\right.$ maximum) and insufficient information to calculate the shape factor inside the spacecraft,

- The heat dissipated from the cameras, star sensors, frame module edges, .etc are neglected,

- All dimensions and configuration are taken from the document Number SRR 62 [2] as a reference, and

- The basis plate configuration is assumed to be square.

The general conduction heat transfer Equation for transient, two dimension, and for equal increments of space coordinates $X=Y$ ) is:

$\left.\left.\mathrm{T}_{\mathrm{m}, \mathrm{n}}^{\mathrm{f}+1}=\quad \sim \quad \mathbf{X}\right)^{2}\left[\mathrm{~T}_{\mathrm{m}+1, \mathrm{n}}^{\mathrm{f}}+\mathrm{T}_{\mathrm{m}-1, \mathrm{n}}^{\mathrm{f}}+\mathrm{T}_{\mathrm{m}, \mathrm{n}+1}^{\mathrm{f}}+\mathrm{T}_{\mathrm{m}, \mathrm{n}-1}^{\mathrm{f}}\right]+[1-4 \quad \sim \quad \mathbf{X})^{2}\right] \mathrm{T}_{\mathrm{m}, \mathrm{n}}^{\mathrm{f}}$ 
for the case of heat generation per unit volume (q'"), the term [q"'( $\left.\left.X^{2}\right) / k\right]$, add to the above Eq. which becomes:

$$
\begin{aligned}
\left.\mathrm{T}^{\mathrm{f}+1}{ }_{\mathrm{m}, \mathrm{n}}=\quad \sim \quad \mathrm{X}\right)^{2}\left[\mathrm{~T}_{\mathrm{m}+1, \mathrm{n}}^{\mathrm{f}}+\mathrm{T}_{\mathrm{m}-1, \mathrm{n}}^{\mathrm{f}}+\mathrm{T}_{\mathrm{m}, \mathrm{n}+1}^{\mathrm{f}}+\mathrm{T}_{\mathrm{m}, \mathrm{n}-1}^{\mathrm{f}}\right] & \left.+\left[\begin{array}{lcc}
1-4 & \sim \\
& +\left[\mathrm{q}^{\prime \prime \prime}\left(\mathrm{X}^{\dot{2}}\right) / \mathrm{k}\right.
\end{array}\right)^{2}\right] \mathrm{T}_{\mathrm{m}, \mathrm{n}}^{\mathrm{f}}
\end{aligned}
$$

Some constant values are: $\left.k_{1}=\quad \sim \quad X\right)^{2}$ and $\left.k_{2}=[1-4 \quad \sim \quad X)^{2}\right]$

The plates material used is $\mathrm{Amg}_{6}$ and the properties of this material are: $(\mathrm{k})$ thermal conductivity $\left(117 \mathrm{~W} / \mathrm{m}^{\circ} \mathrm{C}\right)$, . material density $\left.2627 \mathrm{~kg} / \mathrm{m}^{3}\right), \mathrm{C}$ specific heat $\left(854 \mathrm{~J} / \mathrm{kg}^{\circ} \mathrm{C}\right)$,

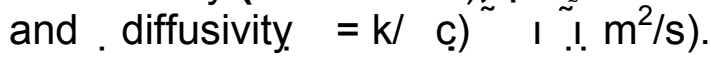

\section{THERMAL ANALYSIS FOR THE PV CELL}

The objectives of the thermal analysis for the Photovoltaics (PV) cell are to determine the maximum and minimum temperatures of the PV cell, which meet the $T$ requirements of the design of spacecraft. We must account for heat inputs from the sun, the earth and electrical and electronic components on board of the spacecraft. In most instances the heat input is highly variable with time, for example the mean value of direct solar heating on spacecraft varies from $1358 \mathrm{~W} / \mathrm{m}^{2}$, when the sun is normal to the surface, to zero in eclipse. The geometry of spacecraft is generally very complex, leading to very complex numerically thermal analysis, however the thermal subsystem accounts for only two to five percent of spacecraft cost and the same of dry weight.

\section{Thermal environment}

Thermal environment such as solar radiation, planetary radiation, and spacecraft heat emission are affecting the design and operation of the PVC and are reported below.

\section{1) Solar radiation:}

a) It is falling at right angles on an area of $1 \mathrm{~m}^{2}$ at solar distance I AU, where AU = $(149598200+500) \mathrm{km}$, is approximately $(1358+5) \mathrm{W} / \mathrm{m}^{2}$, which is called solar constant. The following relation calculates the solar radiation intensity

$$
\mathrm{Js}=\mathrm{P} /\left(4 . \mathrm{D}^{2}\right)
$$

where,

$D$ is the distance from earth to sun $=I A U$ and $P$ is the total power output from the sun $=3.8^{*} 10^{25} \mathrm{~W}$.

b) Planetary or normal albedo is the fractions of the incident solar radiation returned from earth. Earth's albedo varies with its surface conditions. For clouds it is 0.8 , for green areas it ranges from 0.03 to 0.3 , and the average value is about 0.35 (407 \pm 68 $\left.\mathrm{W} / \mathrm{m}^{2}\right)$.

\section{2) Planetary radiation}


The planets of the solar system behave as black body radiation each with an emission satisfies their planetary heat balance equations. The thermal radiation of earth is predominantly infrared with a wave length greater than $1.5 \mu \mathrm{m}$. From this facts it is found that earth thermal infra red emission is $(237+21) \mathrm{W} / \mathrm{m}^{2}$.

\section{3) Spacecraft heat emission}

The spacecraft itself radiates heat into space as black body having a certain value of emissivity. For practical purpose space can be considered as black body at $0{ }^{\circ} \mathrm{K}$ it should be noted that this heat transfer takes place from all spacecraft area.

Thermal analysis technique used for the PVC is studied with assumption that the spacecraft is isothermal with flat plate shape or spherical shape. From the above assumption we find that:

1) The equilibrium $T$ is estimated using an energy balance equation that results from the conservation of energy:

$$
\begin{aligned}
& \text { Absorbed energy + Dissipated energy - Emitted energy }=0 \\
& q_{\text {absorbed }}+q_{\text {dissipated }}-q_{\text {emitted }}=0
\end{aligned}
$$

For body in space the absorbed energy is due to direct and reflected solar energy and earth infrared emission. Energy is dissipated via electronic components and energy leaves the body by electromagnetic radiation.

The absorbed energy, $\mathrm{q}_{\text {absorbed }}=\mathrm{Gs} \mathrm{Ap}$. $\cos$

consider a solar array and assume that the array is thin and isothermal the, the top surface of the array receives direct solar energy while bottom surface receives albedo and earth IR radiation. The direct solar energy absorbed by the array in space is:

Total absorbed energy by the array.

$$
\begin{aligned}
& Q_{A}=Q_{a 1}+Q_{a 2}+Q_{a 3} \\
& (5) \\
& Q_{a 1}=G_{s} A_{r} u
\end{aligned}
$$

The absorbed Earth Infrared radiation on the bottom of the array is given by:

$$
\mathbf{Q}_{\mathrm{a} 2}=\mathrm{IR} \sin ^{2} \quad A_{\mathrm{r}} \mathrm{b}
$$

Where, is the angular earth radius $\operatorname{Sin}^{2} \rho=\mathrm{Re}^{2} /(\mathrm{H}+\mathrm{Re})^{2}$

The solar energy reflected from the earth (albedo) and absorbed by the spacecraft is:

$$
Q_{a 3}=G s \text { a } A_{r}{ }_{b} K_{a} \sin ^{2}
$$


where, $K_{a}$ is the albedo correction factor $=0.664+0.521 \rho-0.203 \rho^{2}$

and $a$ is the albedo percentage of direct solar about $=30 \%$. The total absorbed energy by the array can be obtained by substituting equations $(6,7$, and 9$)$ into Equation (5) to become:

$$
Q_{A}=G s A_{r} u+I R \sin ^{2} \quad A_{r} \quad b+G s \text { a } A_{r} \quad b K_{a} \sin ^{2}
$$

The energy of the array is emitted only by radiation so the energy emitted is:

$$
\begin{aligned}
& Q_{e}=.{ }_{b} A_{r} T^{4}+{ }_{t} A_{r} T^{4} \\
& Q_{e}={ }_{.} A_{r} T^{4}\left({ }_{b}+{ }_{t}\right)
\end{aligned}
$$

where, is the Stefan Boltzmann Constant $=5.67 \times 10^{-8} \mathrm{~W} / \mathrm{m}^{2} \mathrm{k}^{4}$.

Since the solar cells convert solar energy directly to electrical energy there is some dissipation associated with solar arrays (diodes, inter connecting cables, etc.), which is described by solar cell efficiency which is around 0.21 denoted by . The total energy balance Equation (3) becomes:

Gs $A_{r} u_{u}+I R \sin ^{2} \quad A_{r} b+G s$ a $A_{r} \quad b K_{a} \sin ^{2} \quad \therefore A_{r} T_{.}^{4}$.b $y^{-} \quad G s A_{r}=0$

Gs ${ }_{u}+\mathbb{R} \sin ^{2} . \quad{ }_{b}+G s$ a ${ }_{b} K_{a} \sin ^{2} \quad \ldots T_{.}^{4}$.

Solving for this worst case hot T, we find for Gs $=1358 \mathrm{~W} / \mathrm{m}^{2}$

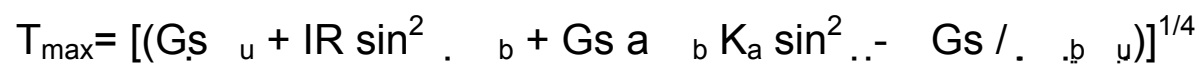

And for worst case cold temperature for $\mathrm{Gs}=0$

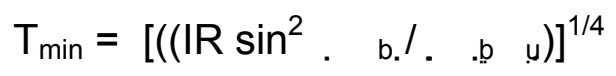

\section{THERMAL ANALYSIS FOR THE SATELLITE EXTERNAL BODY}

The objective of this part is to determine the maximum and minimum temperatures on the satellite body. In order to determine the energy equation for the satellite body, approximate assumptions are made. The total external heat transfer surface area of the satellite body is equivalent to the surface area of a sphere. We can derive the WHC and WCC expressions for sphere similar to the flat- plate expressions. We assume that there is uniform energy dissipation over the surface of the sphere and there is no electrical generation on the spherical surface. The following equation gives the energy balance for the sphere and the T expressions are as follows:

$$
\begin{array}{r}
\mathrm{T}_{\max }=\left[\left(\mathrm{A}_{\mathrm{CS}} \text { Gst } \alpha+\mathrm{A}_{\mathrm{Sph}} \text { F IR } \varepsilon+\mathrm{A}_{\text {Sph }} \text { F Gst a } \alpha \mathrm{K}_{\mathrm{a}}+\mathrm{Q}_{\mathrm{W}}\right) /\right. \\
\left.\left(\mathrm{A}_{\mathrm{Sph}} \sigma \varepsilon\right)\right]^{1 / 4}
\end{array}
$$




$$
\mathrm{T}_{\min }=\left[\left(\mathrm{A}_{\mathrm{Sph}} \mathrm{F} \text { IR } \varepsilon+\mathrm{Q}_{\mathrm{W}}\right) /\left(\mathrm{A}_{\mathrm{SPh}} \sigma \varepsilon\right)\right]^{1 / 4}
$$

Where $F$ is the view factor of an infinitesimal sphere viewing a finite sphere and defines from: $F=(1-\cos \rho) / 2$

\section{RESULT \& DISCUSSION}

\section{THERMAL ANALYSIS FOR THE BASE, BASIS, AND MOUNTING PLATE}

In this section the thermal analysis for the base, basis, mounting plates, and frame module are presented. Table (6) summarizes the location of the equipment and nomenclature used in the numerical analysis for two dimensional heat transfers by conduction for the node locations of equipment on the base plate, basis, mounting plates respectively, which represented the heat sources in the models.

Fig. (4) Illustrates the nomenclature used in two dimensional numerical analysis of heat conduction for base plate, which represented the heat source of the electronic components located on the indicated locations: MBEI SPU at 3.2, MIR \& SS at 3.6, Tel \& MBEI at 6.3, Mag T at 6.5, and MBEI SPU at 6.7. The same two dimensional numerical analysis patterns are used for the basis plate and the mounting plate as shown in Table (6) where the location nodes of the heat source of the equipment on the base, basis, and mounting plates are identified. In order to determine the TD for these electronic components on the base, basis, and mounting plates, the initial $\mathrm{T}$ and boundary $\mathrm{T}$ are assumed to be varying from $(0-30)^{\circ} \mathrm{C}$.

Fig. $(5,6$, and 7$)$ represent the start-up TD for nine family curves as the results of the calculations of the nodes for the satellite base, basis, and mounting plates with various initial $\mathrm{T}(\mathrm{Ti})$ conditions range $(10-30)^{\circ} \mathrm{C}$ and boundary $\mathrm{T}(\mathrm{Tb})$ range conditions $(10-30){ }^{\circ} \mathrm{C}$. The calculation shows that the TD all nodes vary from 15 to $30^{\circ} \mathrm{C}$ for the five heat sources nodes (Tel, SS, MBEI, SPU1, 2, Mt and MIREI) on the base plate. The highest $T$ was found for the Magnetorqure heat source based on the initial and boundary condition temperatures as shown. The Tat the start-up increases with time, based on the $\mathrm{Tb}$, due to the heat dissipation distribution through out the subsystem, then the T become in equilibrium through out the orbital time.

Fig. (8) shows the TD for various heat source nodes on the base plate. At Ti $=10$ ${ }^{\circ} \mathrm{C}$ the nodes $\mathrm{T}$ increases with time then become stable. At $\mathrm{Ti}=30{ }^{\circ} \mathrm{C}$ the node $\mathrm{T}$ decreases with time then becomes in equilibrium. The TDs are decreasing from the $\mathrm{Ti}$ $30{ }^{\circ} \mathrm{C}$ to the $\mathrm{T}$ higher than the $\mathrm{Tb}$ due to the incoming heat dissipation to the subsystems. For $\mathrm{Ti}=20^{\circ} \mathrm{C}$, the TD for nodes: MBEI, SPU1, 2, MIR, and SS are decreased until $500 \mathrm{sec}$ from start-up time, then become constant, while the TD for nodes: MBEl \&Tel, and Mt are increased, then become constant after thermal stability. The combination of variations for the initial and boundary conditions temperatures ranging from $10^{\circ} \mathrm{C}$ to $30^{\circ} \mathrm{C}$ to represent the 9 cases. The variation in TD occurs during almost the first half of the orbital time due to the heat dissipation through out the subsystem, then the T becomes in equilibrium through out the second half of the orbital time. Fig. (9) represents the start-up TD for various nodes on the mounting plate at several initial temperatures range $(10-30)^{\circ} \mathrm{C}$ and boundary layer $\mathrm{T}$ range $(10-30)^{\circ} \mathrm{C}$ Vr time for: SF, MIR-SPU1, MIR-SPU2, and PLCDMS components 
as the heat sources. The initial $\mathrm{T}$ condition affects the component's $\mathrm{T}$ and takes some time to approach the stable temperature.

\section{THERMAL ANALYSIS FOR THE PV CELL}

The $T$ of the photovoltaic cell (PVC) affects the thermal efficiency of converting the solar energy to electrical energy utilizing the PVC. The effects of the solar intensity and the angle between the surface normal and solar vector on the PVC maximum Tare represented in Fig. 10. This angle is inverse proportion with the maximum $T$ while the $T$ is increase with increasing the solar intensity. The thermal performance of the PVC decreases with increasing its maximum temperature, while it is increased with increasing the solar intensity from 1300 to $1400 \mathrm{~W} / \mathrm{m}^{2}$ as shown in Fig. 11. The maximum $\mathrm{T}$ decreases with increasing the satellite altitude as illustrated in Fig. 12. For a given specific orbital altitude, as the solar intensity increases, this maximum $\mathrm{T}$ increases, which may affects the conversion efficiency for the PVC. The environmental conditions, data range, and operating modes used to simulate the PVC and the external body modules are presented in Table (5).

\section{SATELLITE EXTERNAL BODY}

The external satellite surface body is exposed to several heat sources in the space from internal surface (dissipated heat from the equipment) and external surface such as direct solar radiation from the sun, earth emitted IR radiation (diffuse), albedo (diffusely reflected solar), and free molecular heat (as collisions of the body with individual molecules, which can be neglected).

Fig. (13) shows the relationship between the power dissipated from the electronic equipment and the satellite external body's minimum temperature, which increases with increasing the power dissipation. Meanwhile, Fig. 14 represents the effect of the power dissipated on the satellite external body's maximum T with varying the solar intensity from 1300 to $1400 \mathrm{~W} / \mathrm{m} 2$. The satellite external body's T increases either with the power dissipation or the solar intensity. Fig. 15 represents the relationship between the external satellite body's maximum temperatures and solar intensity at various power dissipation $(40-70) \mathrm{W}$. The effect of the satellite altitude on the satellite external body's minimum and maximum temperatures is illustrated in Fig. $(16,17)$ respectively. With increasing the satellite orbital altitude these temperatures are decrease. Also, it is decreased with decreasing the solar intensity.

The start-up TD for the electronic components is explained above. After several orbital, for example 6 orbits, the satellite becomes more stable and the TD can be seen in Fig. (18). The TD for external body for the six satellite surfaces (sides, top, and bottom) with considering the above mentioned environmental and radiation (direct solar radiation, earth emitted IR, and albedo) parameters are shown in Fig. (19) after approaching steady state condition. The satellite has four PVC surfaces. Fig. (20) illustrates the TD for the four surfaces of the PVC after approaching steady state condition.

\section{CONCLUSION}

Analytical and simulation heat transfer models for the base, basis, mounting plates, PV cell, and external satellite surface body are investigated. The thermal analysis and the TD for 
the mentioned components are addressed for steady state and transient modes. From the steady state and the transient solutions of the satellite model we can conclude that the passive thermal control hardware is sufficient and enough for the satellite Egyptsat-1. The results of the analysis are the WHC of $12{ }^{\circ} \mathrm{C}$ and a WCC of $3{ }^{\circ} \mathrm{C}$. The WHC T is below the upper limit of $40{ }^{\circ} \mathrm{C}$ for the electronics. However, the $3{ }^{\circ} \mathrm{C}$ lower limits for the battery have been exceeded. This implies that we must thermally isolate the battery compartment.

\section{REFERENCES}

1. "Album of drawing \& calculations" EGS NRS RPT 00200. Local unpublished document. NARRS, (2002).

2. "SRR 62" EGS NRS RPT 00200. Local unpublished document. NARRS, (2002).

3. Robert D. Karam, "Satellite Thermal Control for System Engineers" Vol. 181 progress in Astronautics \& Aeronautics, American Institute of Aeronautics \& Astronautics, Inc. Virginia 20191-4344, (1998).

4. Larson, Wiley J. and James R. Wertz, "Space Mission Analysis and Design", 3rd. Ed. Kluwer Academic Publishers, London, UK, (1999).

5. Elgendy, Y.A. "Egypt-Sat-1 Mission Analysis Document", Local unpublished document. Egyptian Space Program, NARRS, (2004).

6. Elgendy, Y.A. "Applied Heat Pipe Technology in the Egyptian Microsatellites \& Military Thermal Control Equipment", $12^{\text {th }}$. ASAT Conference, Military Technical Collage, Minister of Defense, Cairo, Egypt, May 29-31, (2007).

7. El-Gendy, Youssef. A., "Analysis of a Plano-Concave Heat Pipe Receiver", Proceedings of the $16^{\text {th }}$ Annual Conference American Solar Energy Society ASES, Denver, Colorado, USA, August 19-23, (1991).

8. El-Gendy, Youssef. A., "Heat Pipe and Desiccant Wheel Dehumidification Technologies", 15 ${ }^{\text {th }}$ World Energy Engineering Congress, 1992, World Environmental Engineering Congress, Atlanta, Georgia, USA, October 28-30, (1992).

9. Gilchrist, W. H. "GSFC Procedures for Layout and Cleaning of thermal blankets," NASA Document 905-G-407, (1977).

10. El-Gendy, Youssef. A., "Simulation of a Dish Ericsson Solar Thermal Power System with Heat Pipe Receiver" Annual Conference American Solar Energy Society ASES, Denver, Colorado, USA, pp. 356-361, June 19-23, (1989).

11. Berger, M.E., and Kelly, W.H., "Application of Heat Pipes to the ATS-F Spacecraft", American Society of Mechanical Engineers, Paper 73-ENAs-45, (1973).

12. A.M. Cruise, J.A. Bowles, T.J. Patrick and C.V. Goodball (1998), "Principles of space instrument design" (1998).

13. P.W. Fortescue and J.P.W. Stark (1991), "Spacecraft Systems Engineering", John Wiley \& Sons Ltd, (1991).

14. Michael D. Griffin, James R. French (1991), "Space Vehicle Design", AIAA education series, (1991).

15. Richard A. Lu, Tanya A. Olsen, and El (June 9, 1995), Building "Smaller, Cheaper, Faster" Satellite within the constrains of an Academic Environment, Satellite System Development Laboratory, Department of Aeronautics and Astronautics, Stanford University, (1995). 
Chart 1 The flow chart diagram for the thermal control system.

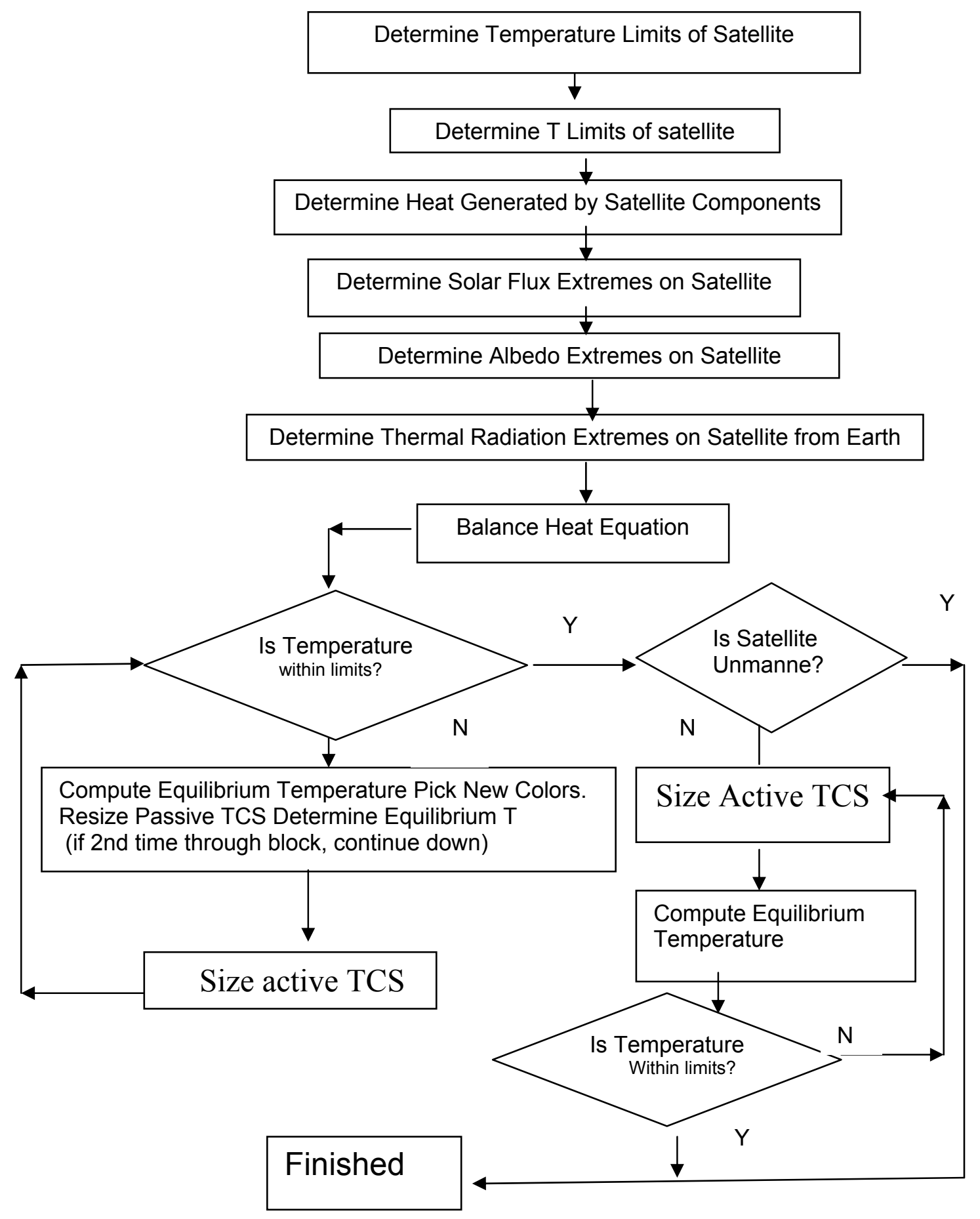


Table (1) Orbital heat loads

\begin{tabular}{|c|c|}
\hline Source & Magnitude \\
\hline Solar Flux & $1371 \pm 10 \mathrm{~W} / \mathrm{m}^{2}$ \\
Summer Solstice & $1313 \mathrm{~W} / \mathrm{m}^{2}$ \\
Winter Solstice & $1429 \mathrm{~W} / \mathrm{m}^{2}$ \\
\hline Earth IR Radiation & $222.78 \mathrm{~W} / \mathrm{m}^{2}$ \\
\hline Albedo & $0.35^{*}(1371 \pm 10) \mathrm{W} / \mathrm{m}^{2}$ \\
\hline Maximum Daily Average Power Dissipation & $78.34 \mathrm{~W}$ \\
Minimum Daily Average Power Dissipation & $24 \mathrm{~W}$ \\
\hline
\end{tabular}

Table (2) Components T limits.

\begin{tabular}{|l|l|l|l|l|l|r|}
\hline Component & \multicolumn{2}{|l|}{ Operational T Limit } & Component & \multicolumn{2}{l|}{ Operational T Limit } \\
\hline & $\begin{array}{l}\text { Lower } \\
\text { Limit }{ }^{\circ} \mathrm{C}\end{array}$ & $\begin{array}{l}\text { Upper } \\
\text { Limit }\left({ }^{\circ} \mathrm{C}\right)\end{array}$ & $\begin{array}{l}\text { Lower } \\
\text { Limit } \\
\left({ }^{\circ} \text { C) }\right.\end{array}$ & $\begin{array}{l}\text { Upper } \\
\left.\text { Limit ( }{ }^{\circ} \mathrm{C}\right)\end{array}$ \\
\hline Magnetometer & 0 & 70 & Module attitude control system & 0 & 30 \\
\hline Electronics & -10 & 40 & Modular power system & 0 & 40 \\
\hline $\begin{array}{l}\text { Communication } \\
\text { Antenna }\end{array}$ & -20 & 60 & Command and data handling & 0 & 40 \\
\hline Structure & -80 & 80 & Propulsion module & 10 & 50 \\
\hline Payload & 15 & 25 & $\begin{array}{l}\text { electronic components of the } \\
\text { power subsystem }\end{array}$ & -10 & 45 \\
\hline Ni-Cd Batteries & 5 & 35 & $\begin{array}{l}\text { heat shield } \\
\text { mounting seats for the optical- } \\
\text { mechanical units of MEl and } \\
\text { middle IR Earth imager, }\end{array}$ & -12 & 10 \\
\hline Solar Cell Arrays & -80 & 80 & & \\
\hline
\end{tabular}


Table 3 Optical properties of the satellite equipment and structural elements

\begin{tabular}{|c|c|c|c|}
\hline $\begin{array}{l}\text { Equipment/ } \\
\text { structural element }\end{array}$ & $\begin{array}{c}\text { Absorption } \\
\text { coefficient, As }\end{array}$ & $\begin{array}{c}\text { Emissitivity factor, } \\
\varepsilon\end{array}$ & $\begin{array}{c}\text { Specific heat, } \mathrm{C} \text {, } \\
\mathrm{J} /\left(\mathrm{kg}^{\circ} \mathrm{C}\right)\end{array}$ \\
\hline $\begin{array}{l}\text { MBEI optical-mechanical } \\
\text { unit }\end{array}$ & $\geq 0.95$ & $\geq 0.92$ & 900 \\
\hline $\begin{array}{l}\text { MBEI signal processing } \\
\text { units }\end{array}$ & $\leq 0.24$ & $\geq 0.85$ & 900 \\
\hline $\begin{array}{l}\text { MIREI optical-mechanical } \\
\text { unit }\end{array}$ & $\geq 0.95$ & $\geq 0.92$ & 900 \\
\hline $\begin{array}{l}\text { MIREI signal processing } \\
\text { units }\end{array}$ & $\leq 0.24$ & $\geq 0.85$ & 900 \\
\hline $\begin{array}{l}\text { Payload command\&data } \\
\text { handling subsystem }\end{array}$ & $\leq 0.24$ & $\geq 0.85$ & 900 \\
\hline $\begin{array}{l}\text { Store\&forward } \\
\text { communication payload } \\
\text { module }\end{array}$ & $\leq 0.24$ & $\geq 0.85$ & 900 \\
\hline $\begin{array}{l}\text { Store\&forward } \\
\text { communication payload } \\
\text { antennas }\end{array}$ & 0.7 & 0.6 & 900 \\
\hline $\begin{array}{l}\text { On-board computer frame } \\
\text { modules }\end{array}$ & $\leq 0.24$ & $\geq 0.85$ & 900 \\
\hline Telemetry module & $\leq 0.24$ & $\geq 0.85$ & 900 \\
\hline Star sensor & $\geq 0.95$ & $\geq 0.92$ & 750 \\
\hline Magnetorquers & $\leq 0.24$ & $\geq 0.85$ & 900 \\
\hline Magnetometer & $\leq 0.24$ & $\geq 0.85$ & 900 \\
\hline GPS receiver frame module & $\leq 0.24$ & $\geq 0.85$ & 900 \\
\hline GPS receiver antenna & 0.7 & 0.6 & 900 \\
\hline $\begin{array}{l}\text { S-band equipment frame } \\
\text { modules }\end{array}$ & $\leq 0.24$ & $\geq 0.85$ & 900 \\
\hline $\begin{array}{l}\text { S-band omnidirectional } \\
\text { antenna-feeder device: } \\
\text { - conical antenna } \\
\text { - dipole antenna }\end{array}$ & $\begin{array}{l}0.5 \\
0.5 \\
\end{array}$ & $\begin{array}{l}0.3 \\
0.3 \\
\end{array}$ & $\begin{array}{l}900 \\
817 \\
\end{array}$ \\
\hline $\begin{array}{l}\text { S-band directional antenna- } \\
\text { feeder device: } \\
\text { - conical antenna }\end{array}$ & 0.5 & 0.3 & 900 \\
\hline $\begin{array}{l}\text { X-band equipment frame } \\
\text { module }\end{array}$ & $\leq 0.24$ & $\geq 0.85$ & 900 \\
\hline X-band antenna & 0.14 & 0.05 & 1000 \\
\hline $\begin{array}{l}\text { Solar array panels } \\
\text { - working side } \\
\text { - backside }\end{array}$ & $\begin{array}{c}0.88 \\
0.9\end{array}$ & $\begin{aligned} & 0.9 \\
& \geq 0.95 \\
&\end{aligned}$ & 800 \\
\hline Battery frame module & $\leq 0.24$ & $\geq 0.85$ & 900 \\
\hline $\begin{array}{l}\text { Cells leveling unit frame } \\
\text { module }\end{array}$ & $\leq 0.24$ & $\geq 0.85$ & 900 \\
\hline $\begin{array}{l}\text { Power conditioning unit } \\
\text { frame module }\end{array}$ & $\leq 0.24$ & $\geq 0.85$ & 900 \\
\hline Base & $\geq 0.95$ & $\geq 0.92$ & 900 \\
\hline Mounting plate & $\geq 0.95$ & $\geq 0.92$ & 900 \\
\hline Protective covers & $\geq 0.95$ & $\geq 0.92$ & 900 \\
\hline Basis unit case & $\leq 0.24$ & $\geq 0.85$ & 900 \\
\hline $\begin{array}{l}\text { Heat shields: } \\
\text { - external surface } \\
\text { - internal surface }\end{array}$ & $\begin{array}{l}\geq 0.95 \\
\geq 0.95\end{array}$ & $\begin{array}{l}\geq 0.92 \\
\geq 0.92 \\
\end{array}$ & 900 \\
\hline
\end{tabular}


Table (4) Daily power consumption and dimensions for subsystem components of the base plate, basis plate, mounting plate, and frame module.

\begin{tabular}{|c|c|c|c|c|c|}
\hline Subsystems & $\begin{array}{c}\text { Daily } \\
\text { Average } \\
\text { Power } \\
\text { Consum } \\
\text { (W) }\end{array}$ & $\begin{array}{c}\text { Overall } \\
\text { Dimensions } \\
(\mathrm{mm})\end{array}$ & Subsystems & $\begin{array}{c}\text { Daily } \\
\text { Average } \\
\text { Power } \\
\text { Consump. } \\
\text { (W) }\end{array}$ & $\begin{array}{c}\text { Overall } \\
\text { Dimensions } \\
(\mathrm{mm})\end{array}$ \\
\hline \multicolumn{6}{|c|}{ BASE PLATE } \\
\hline MIREI & $\begin{array}{l}0,0- \\
0.33\end{array}$ & $435 * 176 * 168$ & Telemetry & $1.5-0.0$ & $190 * 155 * 95$ \\
\hline MBEI & $1.46-0.0$ & $515 * 238 * 228$ & $\begin{array}{l}\text { MBEI } \\
\text { SPU1,2 }\end{array}$ & -0.20 .0 & $300 * 200 * 110$ \\
\hline Magnetorquer & $\begin{array}{l}3.75- \\
3.75\end{array}$ & $180 * 45 * 44$ & Stare Sensor & -1.410 .0 & $373.5 * 254 * 255$ \\
\hline \multicolumn{6}{|c|}{ BASIS PLATE } \\
\hline MIREI & $\begin{array}{l}0,0- \\
0.33\end{array}$ & $435 * 176 * 168$ & Gyro- $\mathrm{x}, \mathrm{y}, \mathrm{z}$ & $5.0-5.0$ & $\varnothing 169 * 49$ \\
\hline MBEI & $1.46-0.0$ & $515 * 238 * 228$ & Magnetometer & -3.753 .75 & $150 * 90 * 102.5$ \\
\hline RWx,y,z & $\begin{array}{c}6.74- \\
5.0\end{array}$ & $141 * 129 * 96$ & Stare Sensor & -1.410 .0 & $373 * 254 * 255$ \\
\hline \multicolumn{6}{|c|}{ MOUNTING PLATE } \\
\hline MIREI & $\begin{array}{l}0,0- \\
0.33\end{array}$ & $435 * 176 * 168$ & $\begin{array}{l}\text { Store \& } \\
\text { forward }\end{array}$ & $0.54-0.0$ & $180 * 175 * 110$ \\
\hline MBEI & $1.46-0.0$ & $515 * 238 * 228$ & $\begin{array}{l}\text { MIREI } \\
\text { SPU1,2 }\end{array}$ & $-0.04-0.0$ & $280 * 100 * 55$ \\
\hline PLCDMS & $\begin{array}{c}1.75- \\
0.0\end{array}$ & $200 * 200 * 100$ & & & \\
\hline \multicolumn{6}{|c|}{ FRAME MODULE } \\
\hline Battery & $2.5-5.0$ & $380 * 326 * 90$ & S-Band 2 & $-0.28-0.0$ & $380 * 326 * 30$ \\
\hline $\begin{array}{l}\text { Cell Leveling } \\
\text { Unit }\end{array}$ & $2.0-0.0$ & $380 * 326 * 40$ & X-Band & $0.46-0.0$ & $380 * 326 * 60$ \\
\hline $\begin{array}{l}\text { Power } \\
\text { Conditioning Unit }\end{array}$ & $7.0-5.5$ & $380 * 326 * 65$ & $\begin{array}{l}\text { ON Board } \\
\text { Computer1 }\end{array}$ & $12.0-9.0$ & $380 * 326 * 38.3$ \\
\hline GPS-Receiver & $1.0-0.0$ & $380 * 326 * 30$ & $\begin{array}{l}\text { ON Board } \\
\text { Computer2 }\end{array}$ & $4.0-1.5$ & $380 * 326 * 38.3$ \\
\hline S-Band 1 & $\begin{array}{c}-0.28 \\
0.0\end{array}$ & $380 * 326 * 30$ & $\begin{array}{l}\text { ON Board } \\
\text { Computer3 }\end{array}$ & -2.02 .0 & $380 * 326 * 38.3$ \\
\hline
\end{tabular}


Table (5) Environmental conditions and operating modes used to simulate the PVC and the external body modules

\begin{tabular}{|c|c|c|}
\hline Characteristics & Data used & Rang \\
\hline \multicolumn{3}{|c|}{ PV Cell } \\
\hline Solar constant Gs $\mathrm{W} / \mathrm{m}^{2}$ & $1358 \mathrm{~W} / \mathrm{m}^{2}$ & $1300-1400 \mathrm{~W} / \mathrm{m}^{2}$ \\
\hline Area of solar array $A_{r}$ & $1.6 \mathrm{~m}^{2}$ & \\
\hline IR energy flux IR & $232 \mathrm{w} / \mathrm{m}^{2}$ & \\
\hline Satellite altitude $\mathrm{H}$ & $668 \mathrm{~km}$ & \\
\hline Earth radius $\mathrm{Re}$ & $6371 \mathrm{~km}$ & \\
\hline Albedo percentage a & 0.35 & \\
\hline Albedo correction factor $K_{a}$ & 0.96 & \\
\hline P.V efficiency $\eta$ & 0.21 & $0.2-0.35$ \\
\hline Angular earth radius $\rho$ & 0.82 & \\
\hline Emissivity of the top surface & 0.9 & \\
\hline Emissivity of the bottom surface & 0.95 & \\
\hline Absorptivity of the top surface & 0.88 & \\
\hline Absorptivity of the bottom surface & 0.9 & \\
\hline \multicolumn{3}{|c|}{ External Body } \\
\hline electrical power dissipation $\mathrm{Q}_{\mathrm{w}}$ & $56 \mathrm{~W}$ & $40-70 \mathrm{~W}$ \\
\hline Emissivity of the sphere & 0.95 & \\
\hline Absorptivity of the sphere & 0.92 & \\
\hline Surface area of the satellite ASph & $2.504 \mathrm{~m} 2$ & \\
\hline $\begin{array}{l}\text { Cross section area of the spherical } \\
\text { satellite ACS }\end{array}$ & $0.625 \mathrm{~m} 2$ & \\
\hline $\begin{array}{l}\text { view factor of an infinitesimal sphere } \\
\text { viewing a finite sphere } \mathrm{F}\end{array}$ & $\mathrm{F}=(1-\cos$ & \\
\hline
\end{tabular}

Table (6) Location nodes of the heat source for the equipment on the base, basis, and mounting plates.

\begin{tabular}{|l|l|l|l|l|l|l|l|l|}
\hline Base & Location & \multicolumn{1}{|c|}{3.2} & 3.6 & 6.3 & 6.5 & 6.7 & & \\
\hline & Equipment & MBEI SPU & $\begin{array}{c}\text { MIR \& } \\
\text { SS }\end{array}$ & $\begin{array}{c}\text { Tel \& } \\
\text { MBEI }\end{array}$ & Mag T & $\begin{array}{c}\text { MBEI } \\
\text { SPU }\end{array}$ & & \\
\hline Basis & Location & 3.4 & 4.5 & 5.5 & 6.3 & 6.5 & 6.6 & 7.2 \\
\hline & Equipment & RWY & RWX & $\begin{array}{l}\text { Gyro \& } \\
\text { RWZ }\end{array}$ & Gyro X & Gyro Y & RWY & M.M. \\
\hline Mount & Location & 3.6 & 5.7 & 7.3 & 7.5 & & & \\
\hline & Equipment & PLCDMDS & MIR & SF & MIR & & & \\
\hline
\end{tabular}

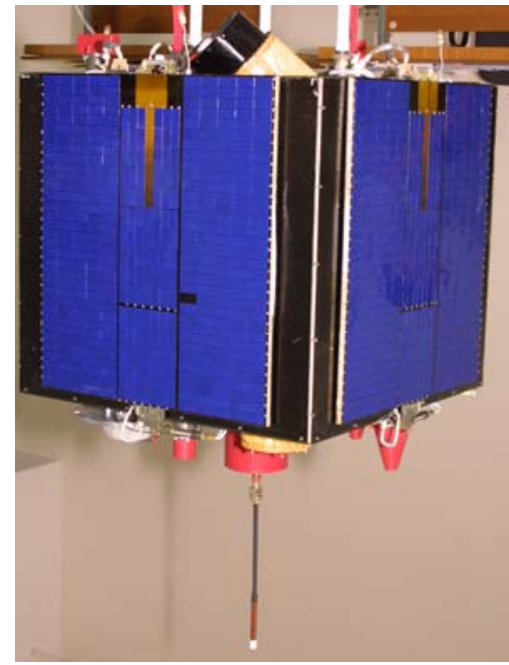

Fig. (1) Satellite general view

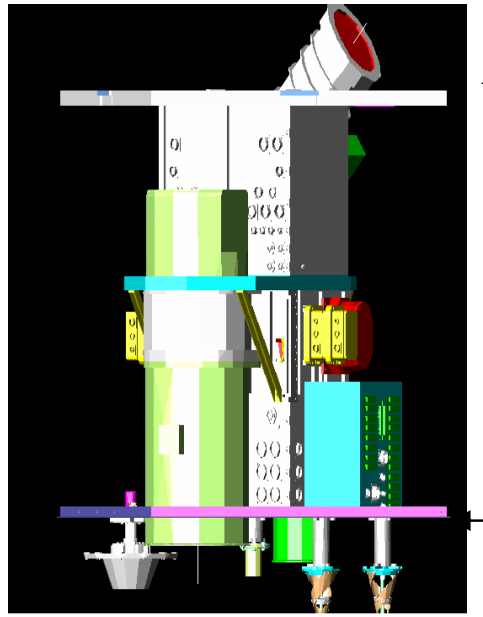

Base plate

Basis 4 plate

Mounting plate

General view inside the satellite 

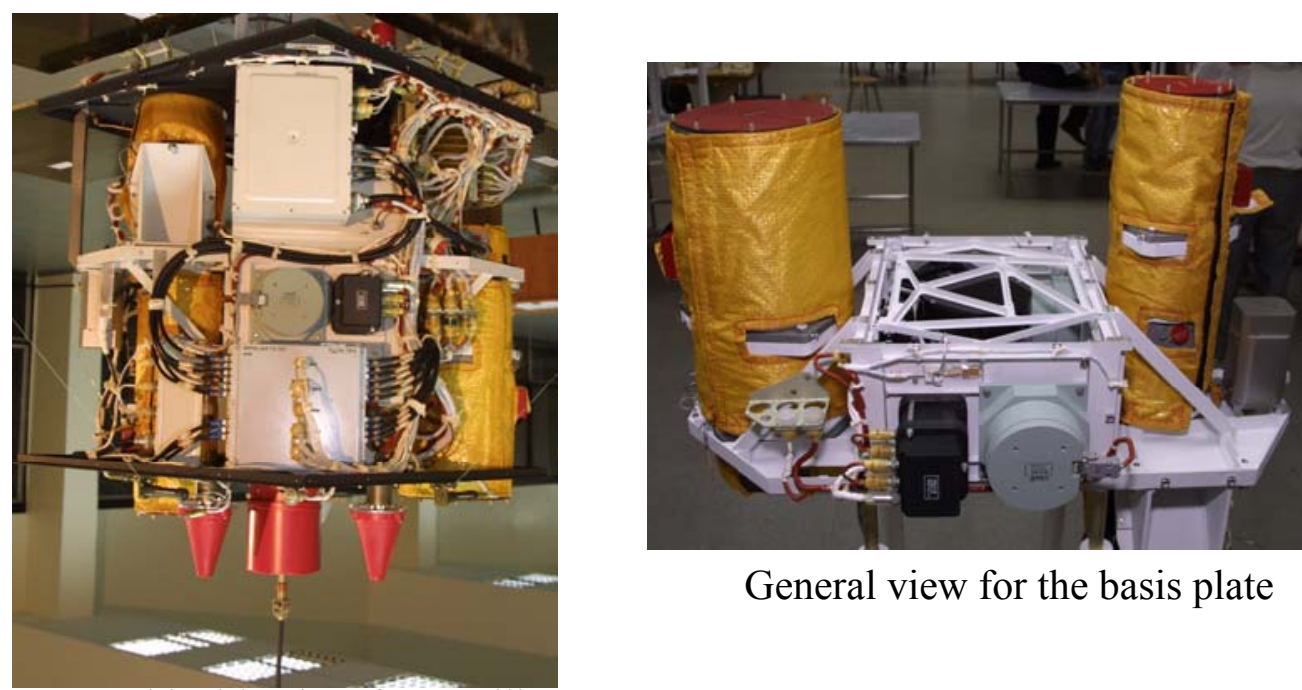

General view for the basis plate

General inside view for satellite
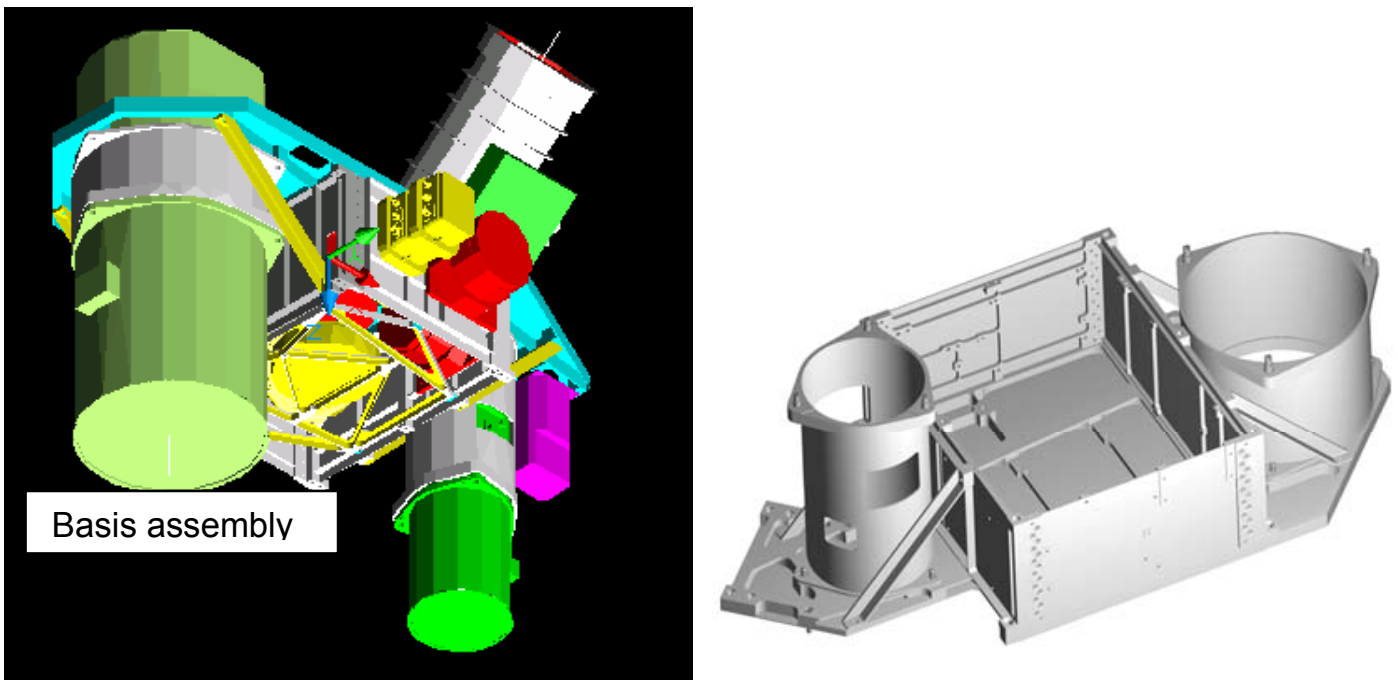

Fig. (2) General view inside the satellite showing the base, basis, and mounting plates.
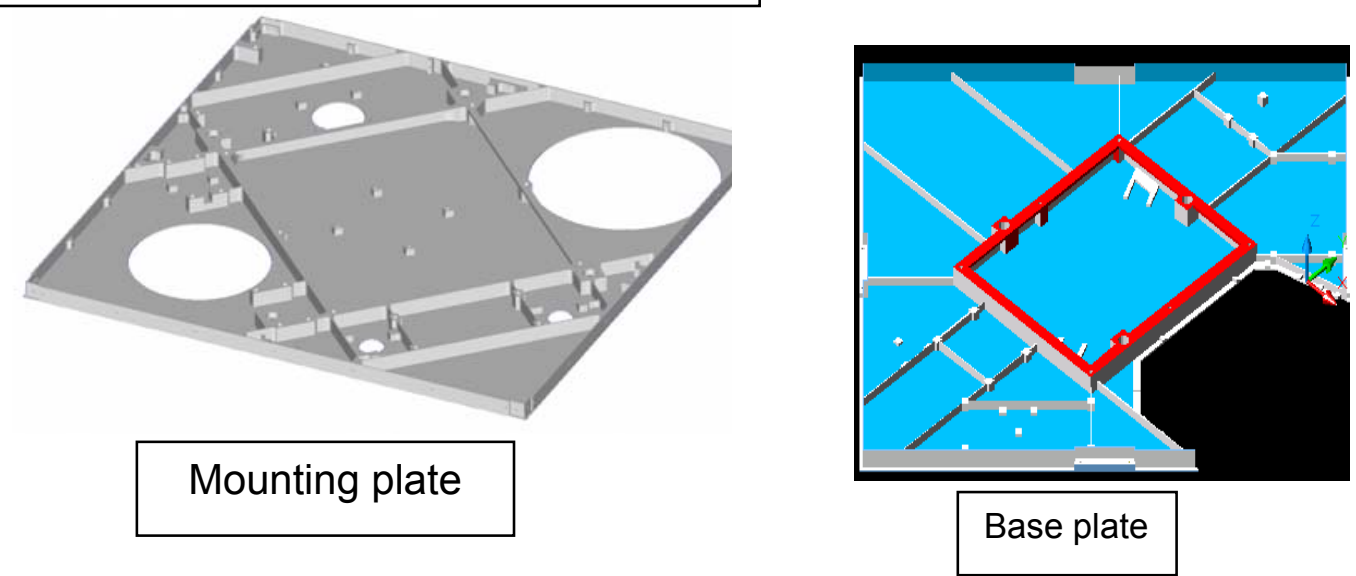

Fig. 3 General view for the base and mounting plates. 


\begin{tabular}{|c|c|c|c|c|c|c|c|c|}
\hline 1.1 & 1.2 & 1.3 & 1.4 & 1.5 & & 1.6 & 1.7 & 1.8 \\
\hline 2.1 & 2.2 & 2.3 & 2.4 & 2.5 & & 2.6 & 2.7 & 2.8 \\
\hline & $\begin{array}{r}0 \\
3.2 \\
\end{array}$ & & & & $0^{3.6}$ & & & \\
\hline 3.1 & \multicolumn{2}{|c|}{3.3} & 3.4 & 3.5 & \multicolumn{3}{|c|}{3.7} & 3.8 \\
\hline 4.1 & 4.2 & 4.3 & 4.4 & 4.5 & & 4.6 & 4.7 & 4.8 \\
\hline 5.1 & 5.2 & 5.3 & 5.4 & 5.5 & & 5.6 & 5.7 & 5.8 \\
\hline .1 & 6.2 & 6.3 & 6.4 & 6.5 & & 5.6 & 6.7 & 6.8 \\
\hline 71 & 7.2 & 7.9 & 7.4 & 7.5 & & 7.6 & 7.7 & 7.8 \\
\hline 8.1 & 8.2 & 8.3 & 8.4 & 8.5 & & 3.6 & 8.7 & 8.8 \\
\hline
\end{tabular}

Heat

Source:

$3.2: \mathrm{MBE}$

$3.6: \mathrm{MIR}$

$6.3:$ Tel

\&SS

\& MBEI

$6.7: \mathrm{MBEI}$

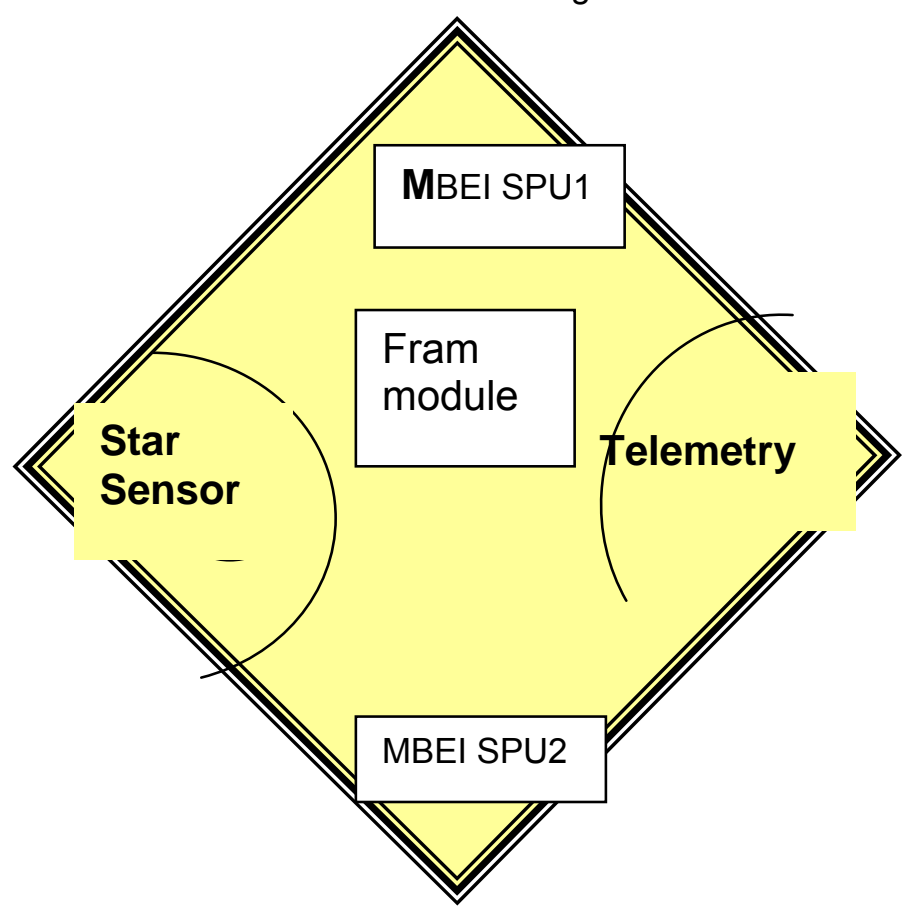

Fig. (4) Illustrating nomenclature used in two dimensional numerical analysis of heat conduction for Base plat. 

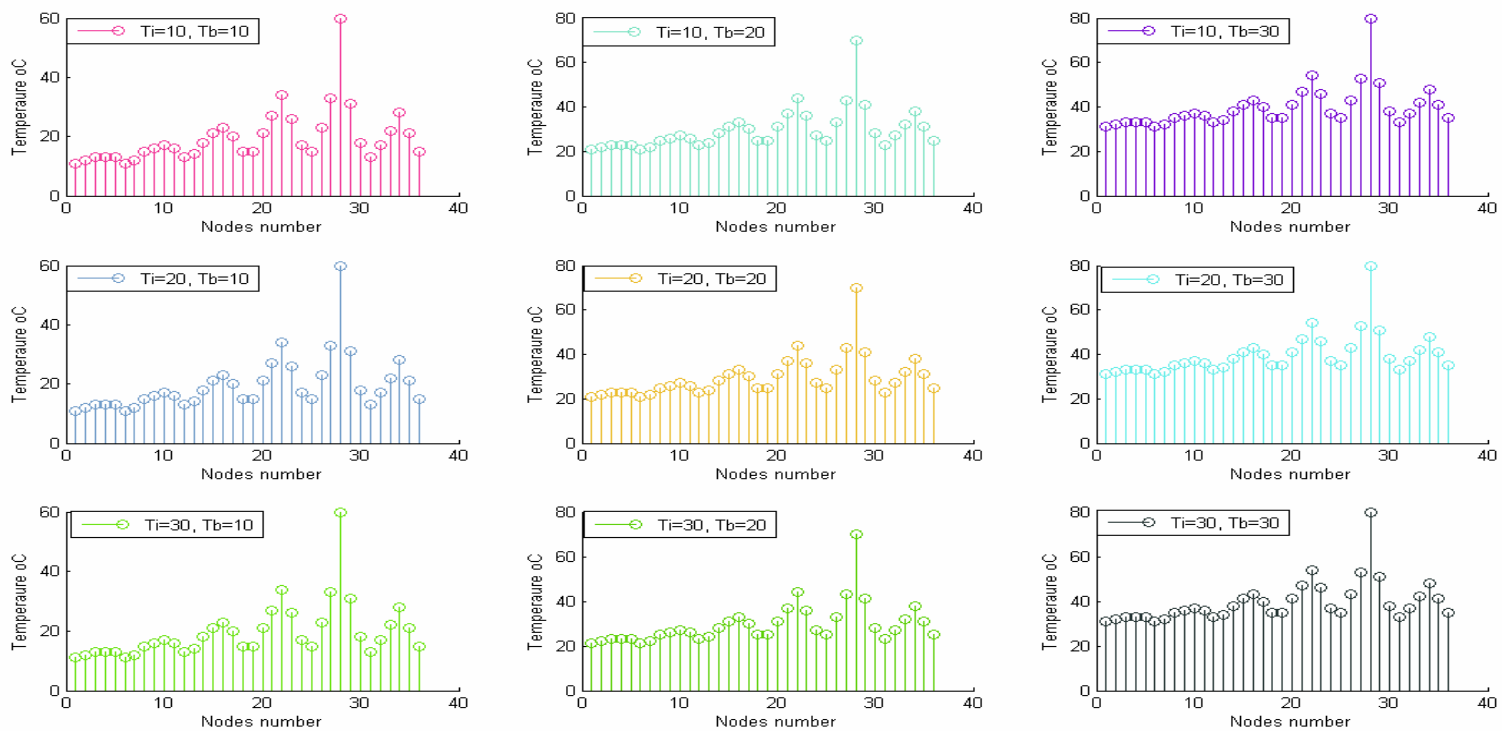

Fig.5 TD at various nodes on the base plate at variable Ti \& Tb.
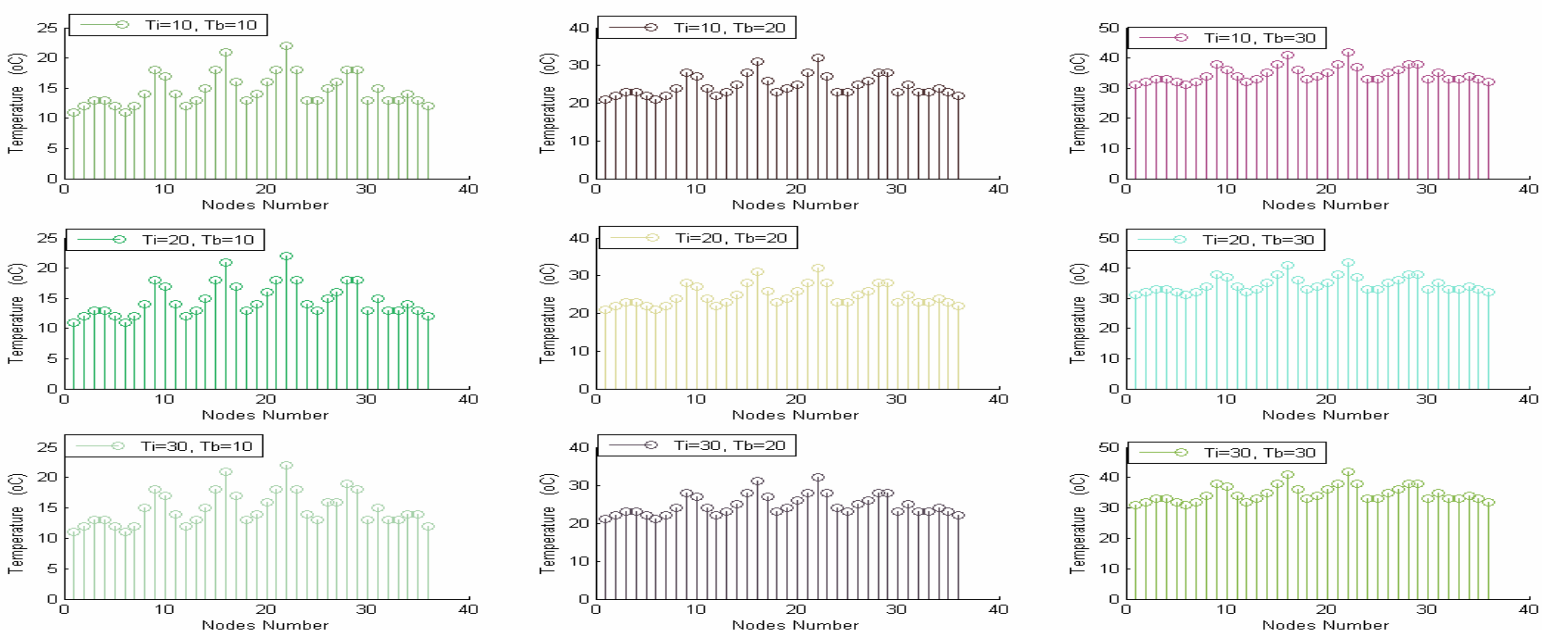

Fig. 6 Temperatures distribution for various nodes on the basis plate at several Ti and Tb.
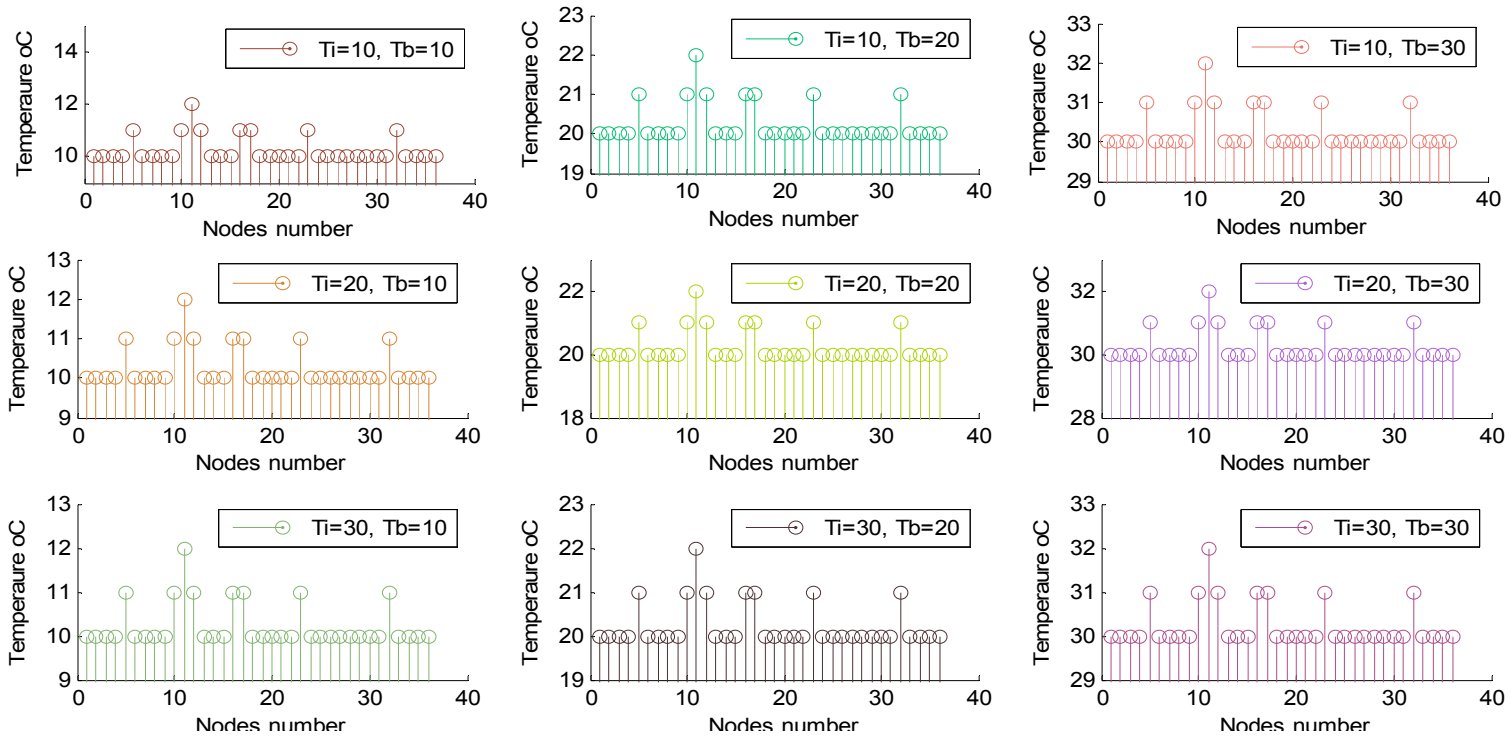

Fig. $7 \mathrm{TD}$ at various nodes on the mounting plate at several $\mathrm{Ti}$ and $\mathrm{Tb}$. 

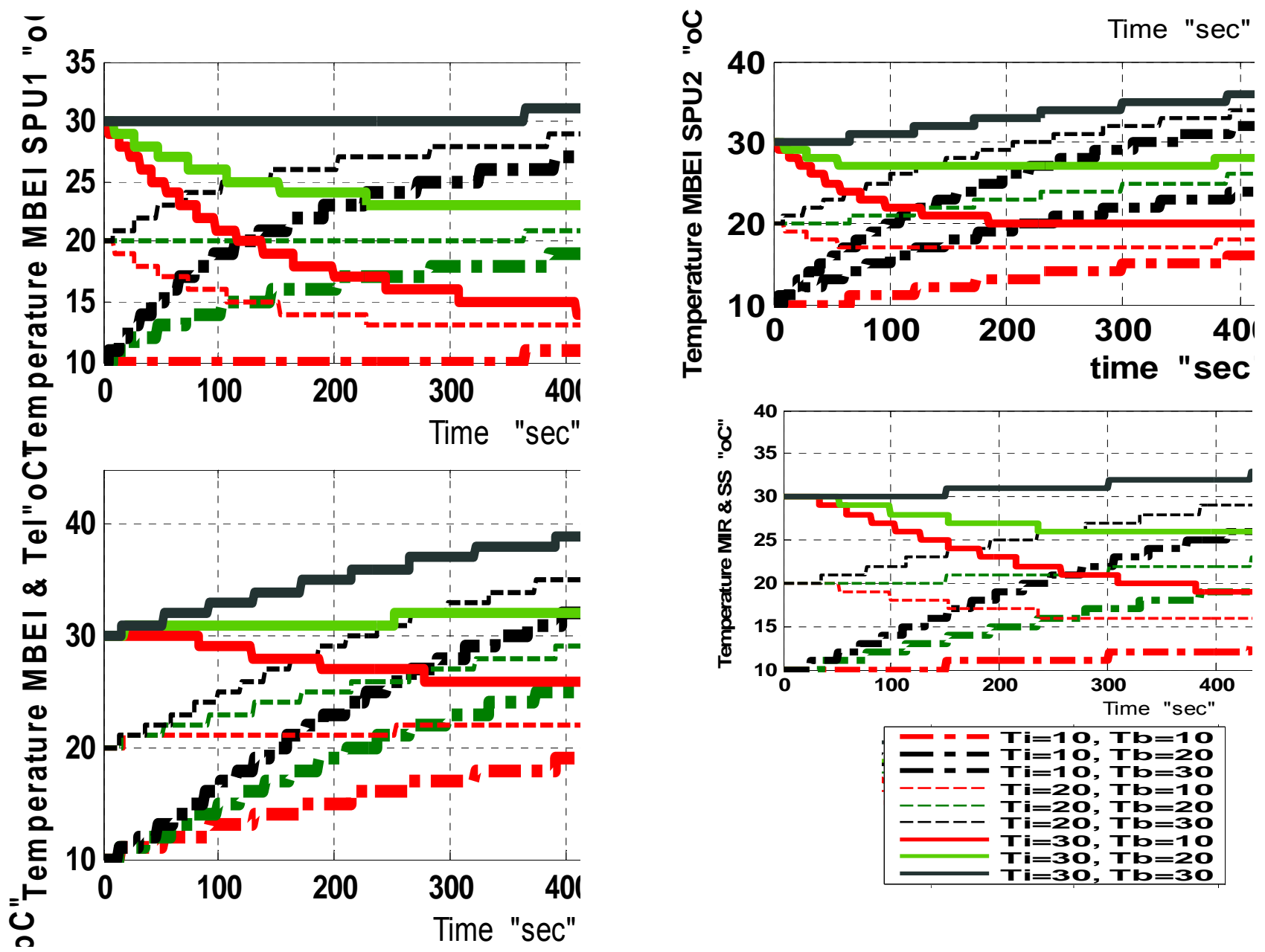

Fig. 8 Temperatures distribution for various nodes on the base plate $\mathrm{Vr}$ Time at several $\mathrm{Ti}$ and $\mathrm{Tb}$.
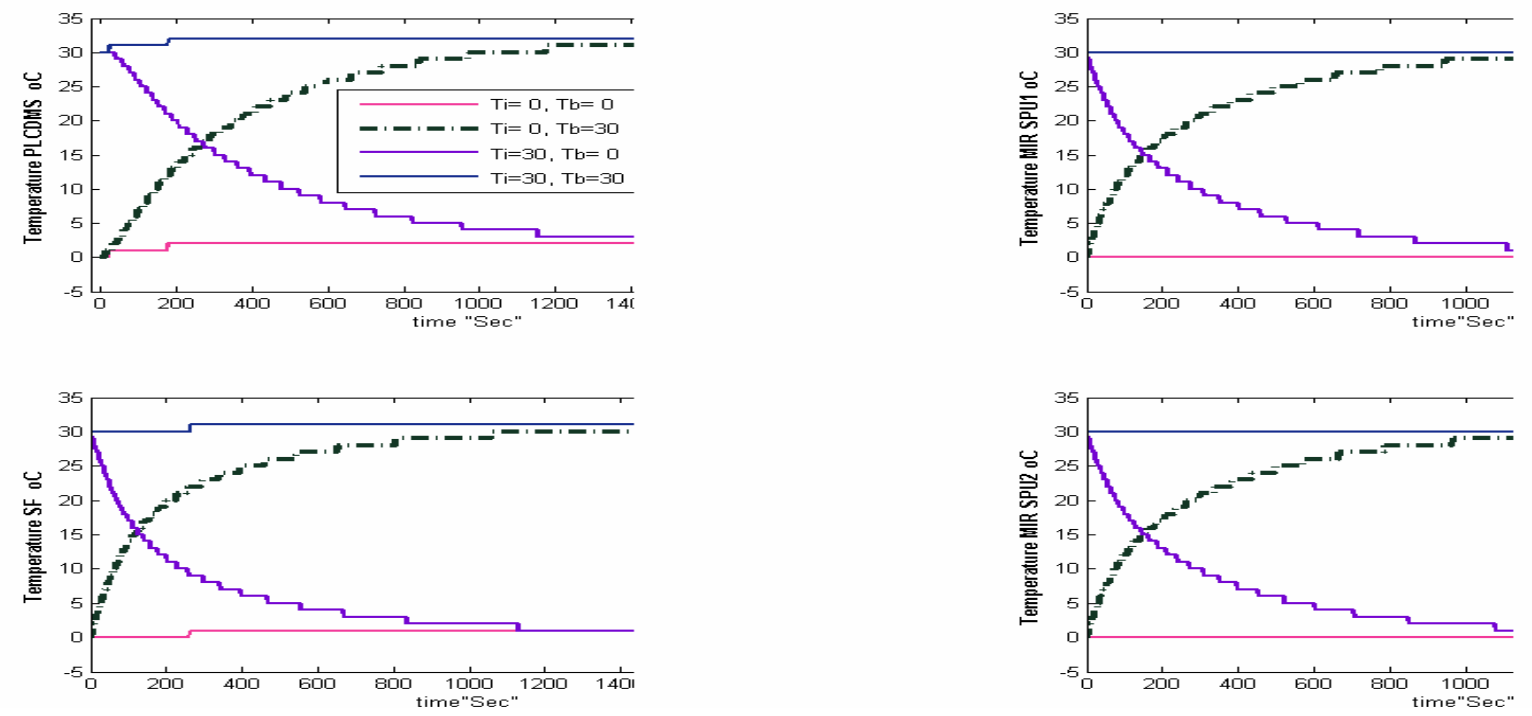

Fig. 9 TD for various nodes on the mounting plate at several initial temperatures range $\left(0-30^{\circ} \mathrm{C}\right)$ and boundary layer $\mathrm{T}$ range $\left(0-30^{\circ} \mathrm{C}\right) \mathrm{Vr}$ time. 


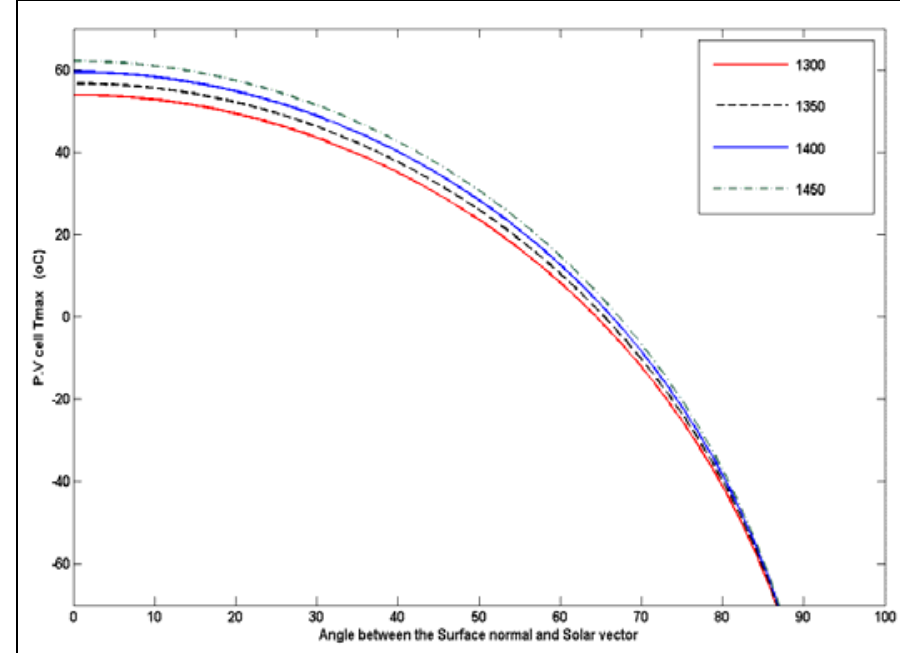

Fig. 10 PVC T Vs the angle between the PVC surface normal and solar vector at various solar intensity

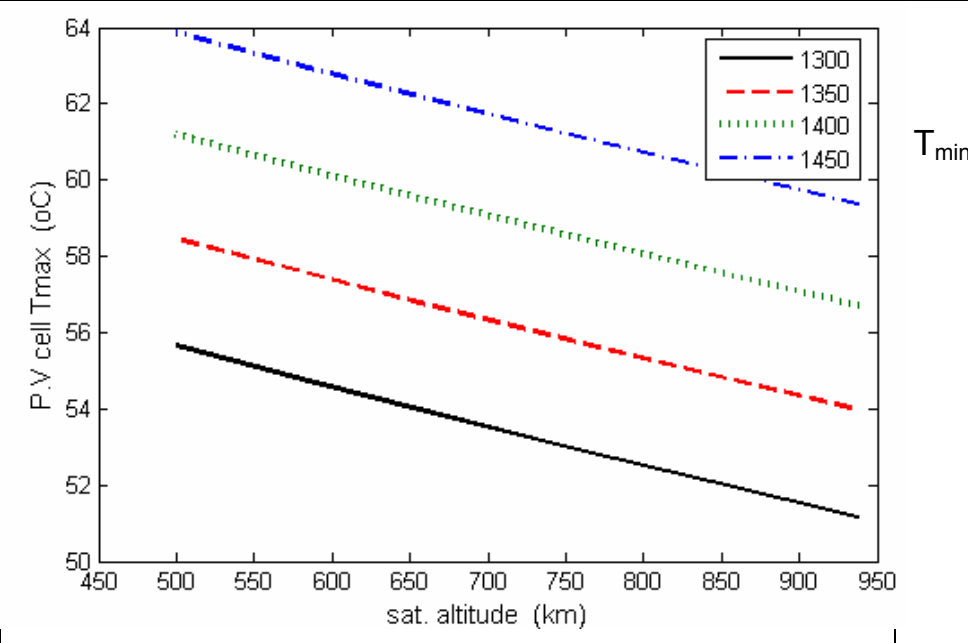

Fig.12 PVC T Vs H at various solar intensity (1300$1400 \mathrm{~W} / \mathrm{m} 2$ )

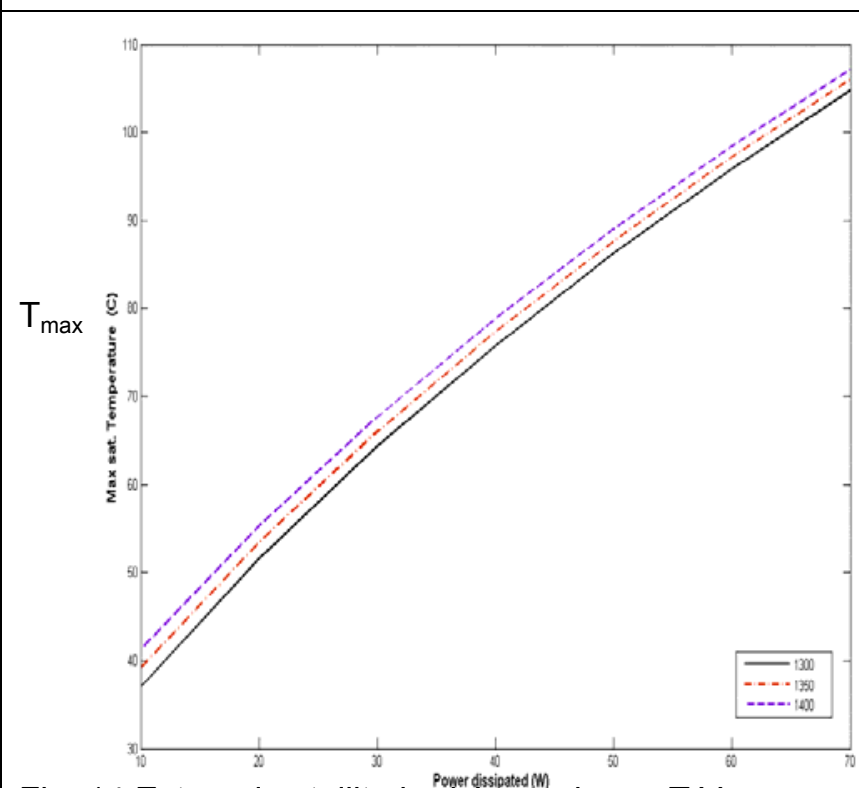

Fig. 14 External satellite body's maximum T Vs power dissipation at various solar intensity $\left(1300-1400 \mathrm{~W} / \mathrm{m}^{2}\right)$

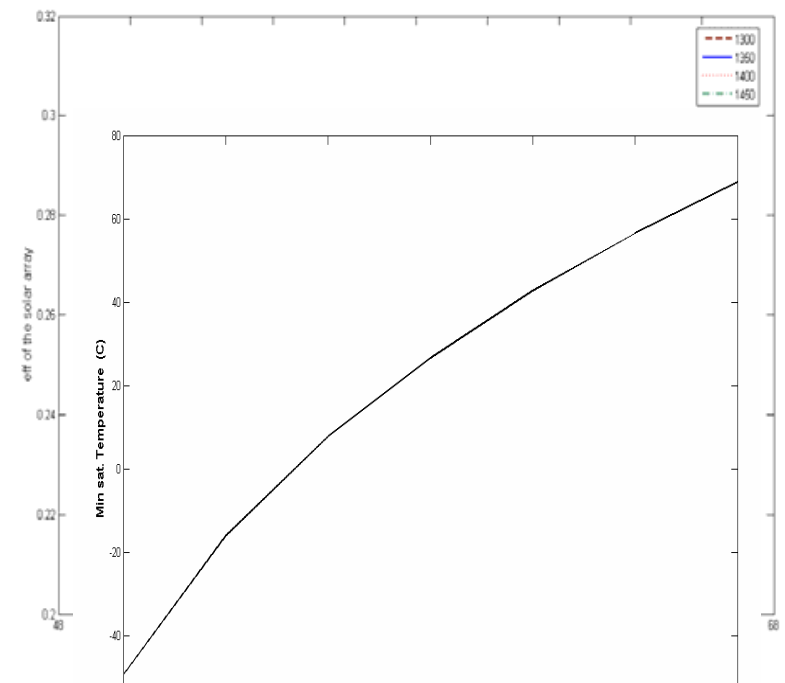

Fig. 11 the effects of the PVC Ton the efficiency at various solar intensity $\left(1{ }^{\circ} 1300^{\prime \prime}-1450 \mathrm{~W} / \mathrm{m} 2\right)$.

\section{$T_{\min }$}

Fig. 13 External satellite body's minimum T Vs power dissipation

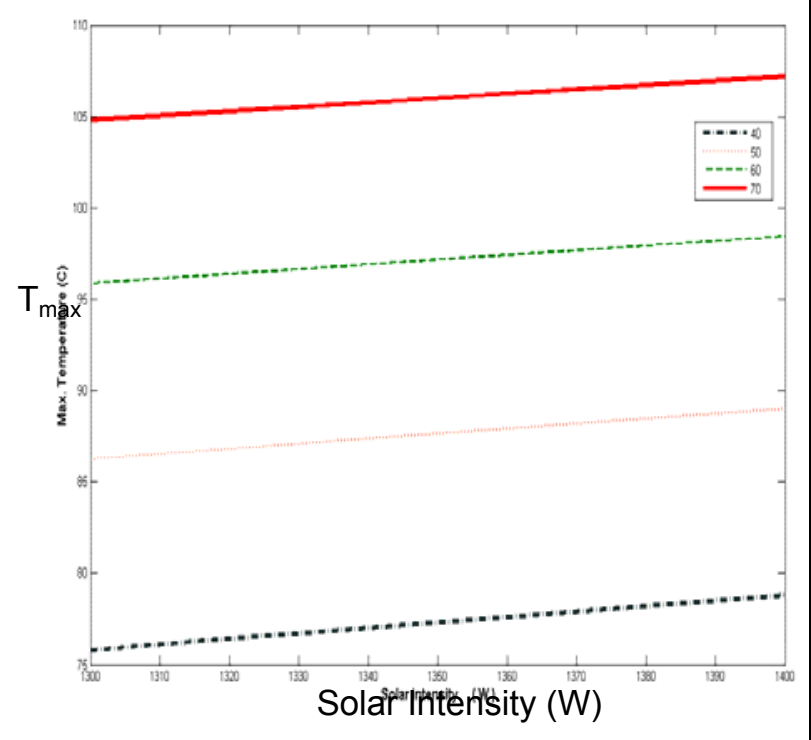

Fig. 15 External satellite body's maximum T Vs solar intensity at various power dissipation (40 - 

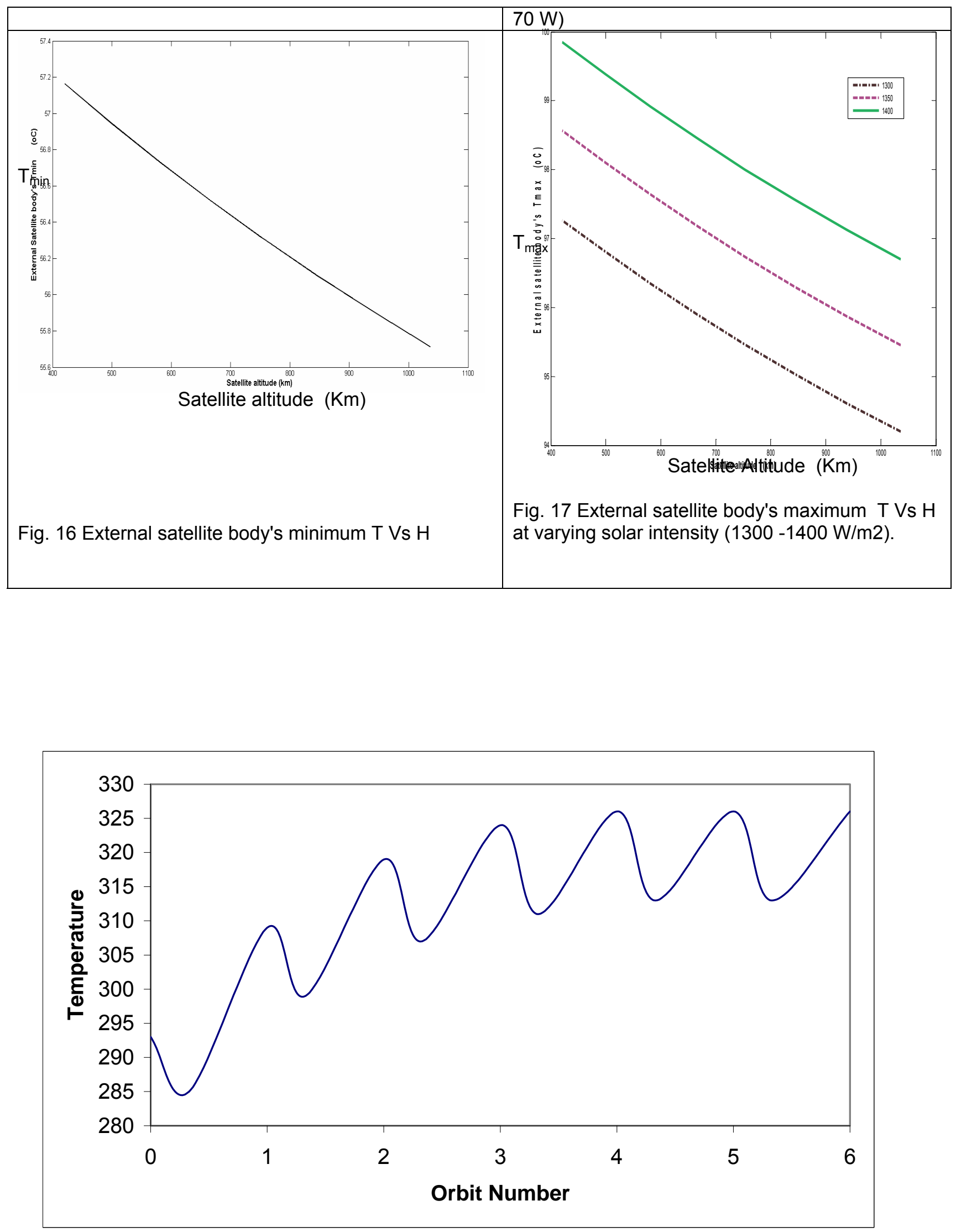

Fig. 18 Satellite transient temperatures 


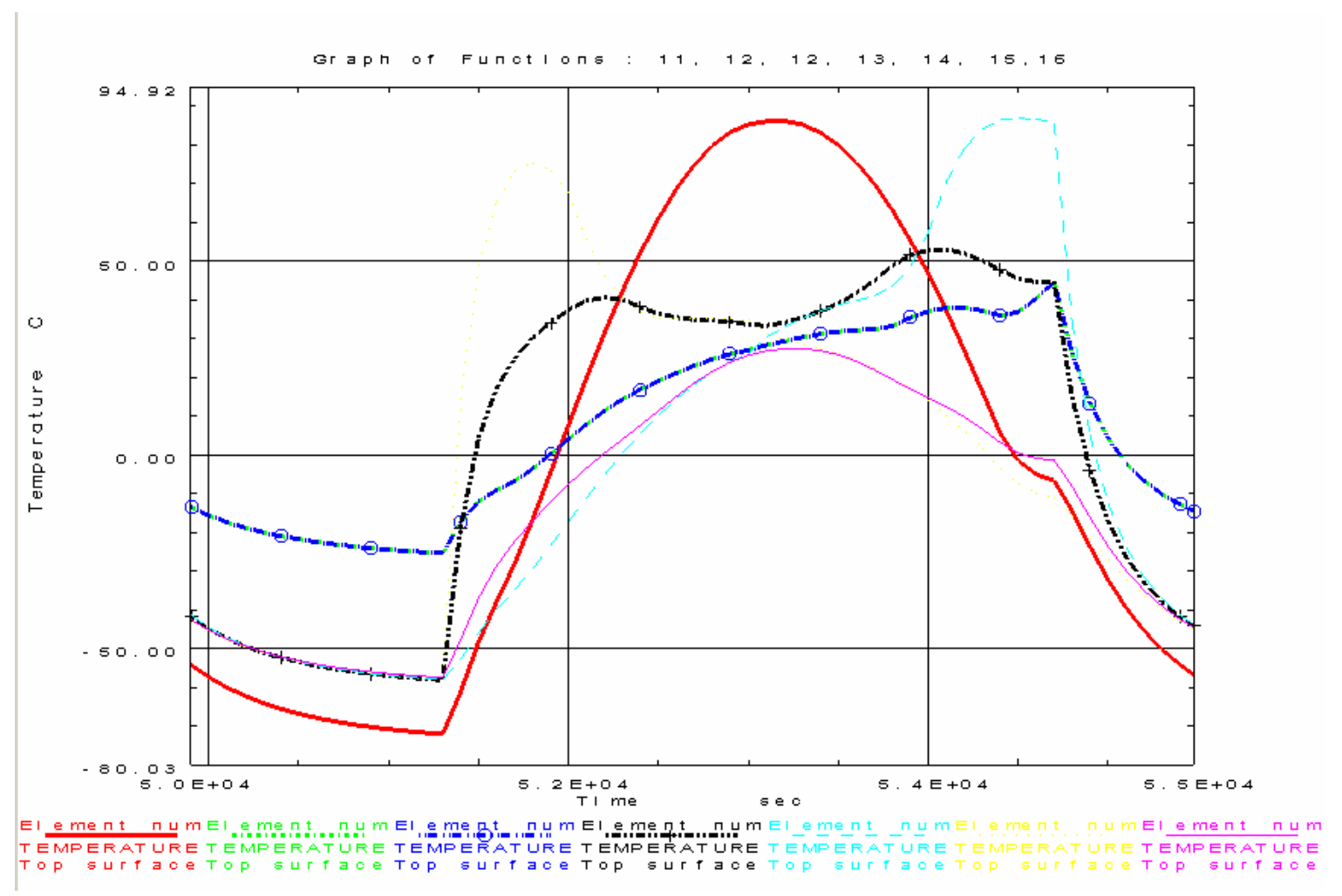

Fig. 19 TD for the six side surfaces of the external body after approaching steady state condition. 


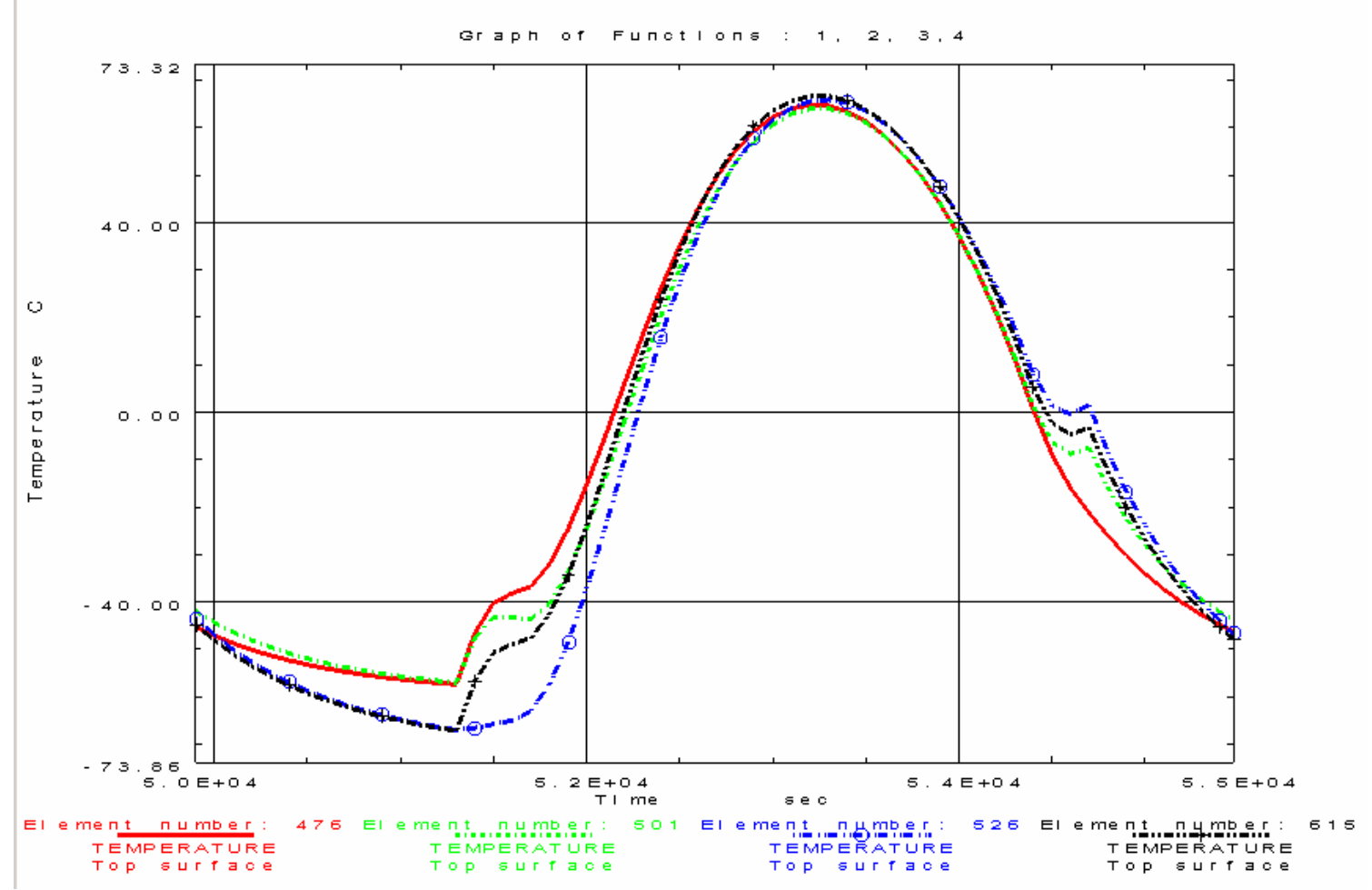

Fig.20 TD for the four surfaces of the PV cell after approaching steady state 